\title{
LA DISOLUCIÓN DE LA SOBERANÍA EN EL ÁMBITO ESTATAL: LOS EFECTOS DE LA INTEGRACIÓN EUROPEA ${ }^{1}$
}

\author{
The disolution of the sovereignty in the state field. \\ The process of european integration
}

\author{
Manuel Fondevila Marón² \\ Máster en Estudios de la UE. \\ Doctorando en Derecho Constitucional \\ en la Universidad de La Coruña (España) \\ fondevila999@hotmail.com.
}

RESUM EN: En la actualidad, la soberanía estatal está siendo discutida por la existencia de dos fenómenos distintos: En primer lugar el proceso de integración Europea. La Unión absorbe cada vez más competencias sobre las que reclama el poder último de decisión, en aras de conseguir una aplicación homogénea del Derecho en todos los Estados miembros. En segundo lugar, la mayoría de Estados miembros están asistiendo a un proceso de descentralización en su interior. Paradójicamente, uno y otro proceso se influyen recíprocamente.

En el moderno Estado Constitucional, el único soberano posible es el Pueblo. Discutir la soberanía estatal implica pues, consecuencias negativas para la democracia.

PALABRAS CLAVE: Unión Europea, Soberanía, Legitimidad, Competencias, Derechos Fundamentales.

ABSTRACT: Nowadays, state sovereignty is being challenged by the existence of two different phenomena. First, the process of European integration. The EU absorbs more competence over which claims the ultimate decision power in order to achieve a uniform application of law in all Member States. Secondly, most member states are witnessing a process of decentralization in its interior. Paradoxically, both processes influence each other reciprocally.

1 Estévez Araujo, J. (Mayo, 1998). “Disolución de la soberanía y fragmentación de la ciudadanía en el proceso de integración europea". Revista Internacional de Filosofía Política no 11, pp. 5-17, p. 5.

2 Artículo recibido el 15 de enero de 2009 y aprobado el 27 de mayo de 2009. 
In the modern Constitutional State, the only possible sovereign is the People. So, to witness state sovereignty implies therefore negative consequences for democracy.

KEY WORDS: European Union, Sovereignty, Legitimacy, Competences, Human Rights.

AGRADECIM IENTOS: A M arta, porque siempre cree en mis proyectos. A sí mismo, quiero mostrar mi agradecimiento a mi M aestro, el Profesor Dr. Javier Ruiperez AlamiIlo, quien sin su ayuda y supervisión nunca hubiese visto la luz este trabajo.

\section{LA SOBERANÍA Y LA LEGITIMIDAD EN EL PLANO ESTATAL}

\section{1) Soberanía}

Existe cierto acuerdo en atribuir a Bodino la primera formulación del concepto de soberanía en su sentido moderno. ${ }^{3}$ En su obra más célebre, Los seis libros de la República la definirá como "el poder absoluto y perpetuo de una República". ${ }^{4}$ Si bien es cierto que el mismo autor señala ya una serie de límites a la soberanía y al soberano, que la Profesora N. García Gestoso sintetiza en los siguientes:

“Unos procederán de la ley divina y del Derecho natural. Otros, del propio orden social comunitario, entre los cuales estarán tanto el respeto a los Tratados Internacionales, contratos y propiedades de sus súbditos, como los derivados de las leyes fundamentales del reino, en especial sucesión en la corona e inalienabilidad del patrimonio". ${ }^{5}$

Los límites son, como se aprecia, fruto de una concepción iusnaturalista que resulta superada en la actualidad y de la necesidad de adoptar ciertas cautelas tras atribuir la titularidad de la soberanía al príncipe soberano. Tanto Bodino como Hobbes, además, se fijan como objetivo la paz en el reino, en un momento de inseguridad. ${ }^{6} \mathrm{La}$ aportación más característica de Bodino, será para H. Heller, el haber sido "el primer pensador que contempló la individualidad del Estado en conexión con las condiciones de vida geográficas y climatológicas". ${ }^{7}$

3 Si bien, como señala la Profesora N. García Gestoso [García Gestoso, N. (2004). Soberanía y Unión Europea. (Algunas cuestiones críticas desde la Teoría de la Constitución). (Barcelona, Atelier)] el concepto surge en el siglo XIII, y otros autores, como Marsilio de Padua y Nicolás de Maquiavelo, ayudan con sus escritos a fundamentar el sustrato sobre el que se asentará el concepto de soberanía y Estado.

4 Cfr. Bodino, J. (1985). Los Seis Libros de la República (Traducc. Pedro Bravo Gala, Madrid, Editorial Tecnos).

5 Cfr. García Gestoso, N. (2004), pp. 40-41.

6 Ibídem, p. 44.

7 Cfr. Heller, H. (1995), La Soberanía. Contribución a la teoría del derecho estatal y del derecho interestatal (M éxico, FCE). Cit., p. 83. 
Este concepto de soberanía ha sido criticado, ya desde el mismo momento de su formulación por un buen número de autores, tanto por su carácter totalitario como desde el punto de vista del pluralismo político. ${ }^{8}$ En efecto, las críticas han provenido de todo tipo de posiciones doctrinales; porque no hay que olvidar que el concepto de soberanía afecta a toda una serie de consideraciones jurídico-políticas de toda clase. Las críticas tienen su origen en el mismo siglo en que escribió Bodino, pero la descomposición del concepto de soberanía no tendrá lugar hasta el siglo XIX, fruto de una serie de movimientos ideológicos. Denunciaba Heller, ya en 1927, que "en nuestros días, el concepto de soberanía (... ) carece de sujeto titular y en consecuencia, de soporte y de patria" y ello como consecuencia de que "en oposición al hombre medieval, el hombre moderno prefirió someterse al poder influenciable e impersonal de la ley, antes que al poder de una persona". ${ }^{10}$ Para Heller, la doctrina de la división de poderes de Montesquieu "no es sino un procedimiento técnico para transformar la volonté générale, portadora y creadora de los valores, en una ley cuya imperatividad no admita perturbaciones", ${ }^{11}$ y así:

"La división de poderes, la idea de la democracia, la doctrina de la corporación, y la teoría de los órganos del estado, tienen como misión hacernos concebir la voluntad del titular de soberanía como una voluntad limpia de toda subjetividad". ${ }^{12}$

A utores como Gierke, Preuss, Duguit, Kelsen y Krabbe se encuentran entre los más celebres críticos a la noción de soberanía desde posiciones que van desde el romanticismo, la doctrina de la corporación, pasando por el sindicalismo radical, y finalmente el positivismo jurídico de la escuela alemana de Derecho Público. ${ }^{13}$ De todas estas corrientes, la que nos importa es la última, por seguir siendo el positivismo jurídico en nuestros días, y a pesar del proceso de revisión crítica al que se ve sometido desde 1945, el paradigma dominante en el estudio y aplicación del Derecho.

Se caracteriza el positivismo jurídico, del que podemos considerar a Kelsen, con su Teoría pura del Derecho y a George Jellinek, con su Teoría General del Estado como sus primeros y más celebres teorizadores, por intentar elaborar una Teoría del Derecho y del Estado, aislando lo jurídico de cualquier tipo de elementos valorativos, políticos, etc., e intentando así mismo delimitar con precisión el campo de las Ciencias Jurídicas de otras ramas del saber como la Economía, la Psicología, o las Ciencias Políticas. La diferencia entre estos dos autores, en lo que al término de soberanía se refiere, es que mientras Kelsen intentará (aunque sin conseguirlo, como apunta Heller), superar dicho término de forma tal que desaparezca de la literatura jurídica, Jellinek afronta el problema de la soberanía, y ofrece una definición del concepto, desde su esquema de

\footnotetext{
Ídem, pp. 62 y ss. Ha de hacerse notar, además, como apuntó H. Heller, que Bodino "pertenece al grupo de autores más frecuentemente citados, pero menos leídos". (Heller, H. (1995), p. 79).

HELLER, H. (1995), p. 85.

10 ídem.

1 Ibídem, p. 87.

12 Ídem.

13 Ibídem, pp. 86 y ss.
} 
pensamiento, como "la propiedad de un Estado, en virtud de la cual exclusivamente a este la capacidad de determinarse jurídicamente y obligarse así mismo". ${ }^{14}$ En el caso de Jellinek se produce además la incoherente circunstancia de que tras haber despersonalizado la noción de soberanía, cuando más adelante en su primera obra distingue entre órganos primarios y órganos secundarios del Estado, acaba equiparando al órgano secundario (el príncipe en el imperio guillermino), a un auténtico soberano.

“Ó rganos secundarios -dirá jellinek- son aquellos que se encuentran, con respecto a otro, en relación orgánica y lo representan de una manera inmediata. El órgano primario representado, sólo puede exteriorizar su voluntad mediante el órgano secundario, y la voluntad de este debe ser considerada como la voluntad inmediata del órgano primario". ${ }^{15}$

Pues bien, lo que pretendo destacar es que al convertir en órgano primario a ese pueblo metafísico, según su concepción, y en órgano secundario a la A samblea, cuando se trate de una República democrática, o al Príncipe, cuand o se trate de una M onarquía (y recordemos que la preocupación de Jellinek se centra fundamentalmente en el imperio alemán de 1871 que vivió), el resultado en la práctica viene a ser que el verdadero soberano dentro del Estado es los representantes (de igual forma que ocurría con la idea de Soberanía Nacional de Sieyès), o el monarca es el verdadero soberano del Estado, ya que según las propias palabras del profesor alemán, "la voluntad de este debe ser considerada como la voluntad del órgano primario". ${ }^{16}$

Si el profesor de Viena (quien no pudo superar por completo la noción de soberanía), acabo atribuyendo la condición de soberano a la Constitución o al Derecho, el profesor de Heidelberg acabará atribuyendo (al menos en un primer momento pues ya hemos visto quien acaba siendo el soberano en Jellinek) la soberanía al Estado como ficción o abstracción, al que se dota de personalidad jurídica. La conclusión de $\mathrm{H}$. Heller acerca de los intentos de este positivismo jurídico por dar una explicación del concepto de soberanía es contundente: “La doctrina del Estado -dirá Heller- no ha logrado hacer comprensible al Estado como sujeto de la soberanía (... La soberanía de una ficción o aún de una abstracción (El Estado) es inimaginable". ${ }^{17}$

Carl Schmitt define la soberanía, diciendo que soberano es "aquel que decide sobre el estado de excepción". ${ }^{18}$ Por estado de excepción entiende el autor un concepto general de la teoría del Estado y no un decreto de necesidad o al Estado de sitio como fenómenos aislados. En su pensamiento la soberanía se configura como un concepto

14 Cfr. Jellinek, G. Teoría general del Estado (Traducc. Fernando de los Ríos. Granada, Editorial Comares). Cit., p. 473.

15 Ibídem, pp. 539 y 540.

16 Quiero dejar constancia de mi agradecimiento al Profesor J. Ruiperez Alamillo, de cuyos planteamientos soy deudor.

17 HeLler, H. (1995), p. 149.

18 Cfr. Schmıт, C. (1998), Teología Política. Cuatro ensayos sobre la soberanía (Buenos Aires, Editorial Struart \& Cía.). Cit., p. 15. 
límite, en el sentido de estar referido a casos fuera de la normalidad o extremos. Según Heller, a esta concepción:

"Se le debe reconocer el mérito de haber considerado con razones excelentes y en oposición a la doctrina imperante en nuestros días, que el problema de la soberanía es el problema de la decisión mediante una individualización de la voluntad. Pero Schmitt, que en términos generales ve en el Estado una dictadura de la voluntad, no ha podido, como tampoco logró Kelsen en su defensa del estado de derecho liberal racionalista, descubrir una unidad de voluntad como sujeto de la soberanía". ${ }^{19}$

Se pregunta Heller si correspondería la titularidad de la soberanía al Presidente de la República, conforme a una interpretación del art. 48 RW. ${ }^{20}$ Es muy probable que eso sea lo que subyazca en el pensamiento del profesor de Berlín, al menos para el caso concreto de Alemania, afirma más adelante que porque los Estados alemanes, no pueden, en función del art. 48, declarar el Estado de excepción, no se puede decir de ellos que sean soberanos. ${ }^{21}$

La soberanía es pues definida por Heller como "la cualidad de la independencia absoluta de una unidad de voluntad frente a cualquiera otra voluntad decisoria universal efectiva". ${ }^{22}$ Pero lo verdaderamente característico de Heller es haber atribuido la titularidad de la misma al "Pueblo como unidad"23 (la cursiva es mía).

Hacer una exposición más pormenorizada, de la génesis, evolución y críticas al concepto de soberanía excedería con mucho los límites materiales de este trabajo, es por ello que conformo con dejar ahora constancia de dos cuestiones fundamentales, sobre las que en todo caso habremos de volver después: 1) En la actualidad, resulta unánimemente aceptado que, en el seno de un Estado democrático de Derecho, el único soberano posible es el pueblo en su conjunto. La cuestión, que tan pacífica resulta en nuestros días, ha sido objeto en el continente europeo de una lucha secular de la burguesía frente a las monarquías absolutas, de tal forma que no es hasta la generalización del sufragio universal, y sobre todo a partir de 1945 cuando consiga afianzarse en Europa el principio democrático. Ello se debe, por un lado, a que La Soberanía Popular, teorizada por J.J Rousseau y reivindicada en el plano de los hechos en las revoluciones burguesas, se encuentra en el viejo continente, por contraposición a lo que ocurre en los Estados Unidos de América, contrarrestada por la idea de Soberanía Nacional, preconizada por Sieyès, y entonces ocurre, en palabras del Profesor P. De Vega, que "De esta forma establecía las bases que le permitirán introducir la mecánica representativa en el ejercicio del Poder Constituyente (...) El Poder Constituyente deja de ser entonces el poder en el que pueblo directamente participa, como titular indiscutible de la soberanía,

Cfr. Heller, H. (1995), p. 158.

20 Ibídem. p. 155.

21 Cfr. Sснміт, C. (1998), p. 23.

22 Cfr. Heller, H. (1995), p. 197.

23 Ibídem, p. 168. 
para convertirse en el poder de las A sambleas, en las que la Nación delega sus competencias". ${ }^{24}$ Por otro lado, la pervivencia del principio monárquico, hizo surgir las primeras formulaciones de la soberanía dividida, entre la asamblea y el monarca. Como es bien sabido, los logros en materia de libertades obtenidos tras la Revolución Francesa se frustran en el siglo XIX durante la Restauración. 2) Lo que resulta, no obstante, discutido, es si el Pueblo como Poder Constituyente es, en efecto, según la concepción clásica una "res facti non iuris". ${ }^{25}$

Y por tanto un poder prejurídico, absoluto, e ilimitado tanto en las formas como en el contenido, o si por el contrario, existen límites materiales internacionales a ese poder constituyente, como sostiene, por ejemplo, el Profesor LMa Díez-Picazo. ${ }^{26}$ Para este autor, los límites al Poder Constituyente serían: a) En primer lugar, los Derechos Humanos. b) En segundo lugar, los Tratados Internacionales. c) En tercer lugar, determinados acuerdos para armonización en una materia dada, como los adoptados en el seno del Consejo de Europa en una materia dada, como los adoptados en el seno del Consejo de Europa. d) Señala también Díez Picazo que la aplicación de los Tratados internacionales sobre Derechos Humanos tiene repercusión en aspectos institucionales u orgánicos de derecho constitucional nacional, por ejemplo en materia de ilegalización de partidos políticos. e) Por último, sostiene el autor que para existe una exigencia de forma democrática en el ámbito europeo y para los países que se hayan suscrito al Pacto Internacional de Derechos Civiles y Políticos, a causa de lo dispuesto en el artículo 25.

Ello supone un menoscabo del principio democrático, en tanto que los sujetos en la Teoría del Poder Constituyente y del Pacto Social en Rousseau, son los ciudadanos del Estado, mientras que los sujetos de Derecho Internacional siguen siendo hoy, fundamentalmente los Estados. Se sustituye así la legitimidad democrática directa por, en el mejor de los casos, una legitimidad democrática indirecta.

Además de la confusión, ya apuntada, a la que llevó la doctrina de la Soberanía Nacional preconizada por Sieyès, con posterioridad, el positivismo jurídico, con su postulado de la personalidad jurídica del Estado, al que se confiere la soberanía, y que exige el entendimiento del pueblo como una unidad monolítica, llevan, como ha denunciado el Profesor P. De Vega, a una negación absoluta del principio democrático. De todo ello resulta, que el pueblo, entendido como señala el profesor P. De Vega, como una unidad monolítica, de tal forma que se ignora la pluralidad de elementos sociales, opiniones, e intereses que se da en su interior, es reducido a un mero órgano de ese Estado y así -dirá Jellinek- "En ambas formas de democracia, la inmediata y la representativa, el pueblo es el órgano del Estado". ${ }^{27}$

24 Cfr. DE VEGA, P. (1998 a), "La reforma constitucional y la problemática del poder constituyente" (M adrid, Editorial Tecnos). Cit., p. 32.

25 Ibídem, pp. 24 a 38.

26 Cfr. Diez PICAzo, LM. (2006), "Límites internacionales al Poder Constituyente". Revista Española de Derecho Constitucional no 76 (Enero-A bril), pp. 9-32.

27 Cfr. De VeGA, P. (1998 b), "El tránsito del positivismo jurídico al positivismo jurisprudencial en la doctrina constitucional". Teoría y Realidad Constitucional no 1, pp. 65-88. Cit., p. 74. 
En la actualidad, lo que está ocurriendo es que asistimos a un doble proceso de disolución de la soberanía en el ámbito estatal, provocado por un doble orden de fuerzas, centrífugas y centrípetas, que tienen lugar como consecuencia de los procesos de mundialización y regionalización:

1) Por un lado, en palabras del Profesor P. De Vega: “Implica la mundialización una amenaza que pone en peligro el concepto clásico de soberanía (... ) sucede no obstante, que por residir la esencia de ese poder soberano, no tanto en la condición de poder absoluto y perpetuo como en el hecho de expresar la voluntad democrática del Pueblo, su eliminación conlleva el aniquilamiento de los principios vertebradores que, desde el renacimiento a nuestros días, sivieron para dar sentido y coherencia al vivere político de los hombres sobre la tierra". ${ }^{28}$

Concebida, desde esta perspectiva democrática, el peligro para la soberanía se produce como consecuencia, también apuntada por el autor, de la reducción de los espacios políticos. ${ }^{29}$ Lo que ocurre, en mi opinión, es que se está alejando al ciudadano de la toma de decisiones, como demuestra el hecho de que en el ámbito europeo, el sujeto principal sigue siendo el Estado y no el individuo. No existe un espacio de discusión europeo: los individuos disponen de poca información acerca de los asuntos que se están ventilando en las instituciones europeas (que siguen siendo de carácter eminentemente interestatal), y las medidas tampoco son objeto de debate por parte de los parlamentos nacionales, y rara vez objeto de atención por parte de los medios de comunicación. Pero así mismo me interesa destacar, que todo ello ha sido favorecido por la aquiescencia de los individuos mismos, quienes en mi opinión, y por emplear la terminología rousseauniana, siendo los verdaderos sujetos de la soberanía, se han conformado, dado el buen nivel de vida en general del mundo occidental, con ser libres en lo privado, aún a pesar de ser esclavos en lo público. A sí las cosas, asistimos en la actualidad a un cambio de paradigma, que se manifiesta en el paso de la ideología del constitucionalismo a la ideología de la Constitución, ${ }^{30}$ que se explica, siguiendo al Profesor P. De Vega, porque los nuevos poderes fácticos, que la Constitución debería controlar, no se presentan como adversarios del sistema de principios y valores constitucionales, sino que al proclamar el fin de la historia (Fukuyama) o el fin de las ideologías (Bell), lo que se pretende es consagrar la realidad constitucional que, sin embargo, la mundialización está aparatosamente desmontando. En estas circunstancias, cuestionados los supuestos ideológicos de la sociedad civil sobre los que se asentó la constitución normativa (García Pelayo. Derecho Constitucional Comparado. p. 34), afirma el Profesor P. De Vega que: "Nada tiene de particular que se produzca un giro copernicano en la historia del constitucionalismo, en virtud del cual la Constitución deja de ser la norma legitimada en los valores que conforma su propia realidad

28 Cfr. De Vega, P. (2003). “La democracia como proceso. (Consideraciones en torno al republicanismo de Maquiavelo). Revista de Estudios Políticos no 120. (A bril-Junio), pp 7-43. Cit., p. 38.

29 Cfr. De VEGA, P. (1998 c). “Mundialización y Derecho Constitucional. La crisis del principio democrático en el constitucionalismo actual". Revista de Estudios Políticos no 100, pp. 13-56. Cit., p. 13.

30 Ibídem, p. 34. 
social y política, para pasar a convertirse parte en instrumento legitimador de un mundo confuso, desordenado y caótico". ${ }^{31}$

2) En el plano infraestatal, los ataques a la soberanía estatal como consecuencia del proceso de descentralización son dos, y han sido señalados recientemente por mi Maestro:32 a) En primer lugar las tesis del nacionalismo vasco de que, habida cuenta de lo dispuesto en los artículos 10.2, 95.1 y 96 de la Constitución, los respectivos artículo 10.1 del Pacto Internacional de Derechos Civiles y Políticos y del Pacto Internacional de Derechos Económicos Sociales y Culturales, se encuentran hoy vigentes no sólo en aquello que no contradice a la Constitución de 1978 sino en aquello en que sí lo contradice. De ahí deduce el nacionalismo vasco, y todos los demás nacionalismos de ámbito regional, la posibilidad de poder ejercitar de inmediato el ius seccesionis, incluso manteniéndose vigente el actual Texto Constitucional. b) En segundo lugar, y en el seno de las reformas estatutarias de 2004, la introducción en los nuevos estatutos de autonomía de declaraciones de derechos deberes y principios, que toman de referencia, como ha indicado Raúl Canosa, no el Título I de nuestra Constitución sino la Carta Europea de Derechos Fundamentales de 7 de diciembre de 2000. Las críticas que de la tesis del nacionalismo vasco acerca del Derecho de autodeterminación cabe hacer son de dos tipos: 1) una crítica general sería la crítica al monismo jurídico, en sus dos vertientes moderado y radical. A este respecto transcribo literalmente, por su acierto y claridad, las críticas que a tal efecto, ha realizado mi Maestro. Del monismo jurídico moderado dirá: "En virtud de su propio razonamiento (del monismo jurídico moderado), las normas internacionales declarativas de Derechos pierden su carácter internacional. Y es que en efecto ocurre que la única manera posible de concebir a la Comunidad Internacional como titular de la soberanía, es la de afirmar que el proceso altusiano de creación del cuerpo político ha conocido un paso más: la celebración de un pacto social entre los diversos Estados hasta entonces soberanos e independientes. Con ello, innecesario debiera ser advertirlo, la Comunidad Internacional se transformaría en un único Estado, como unidad de organización y de decisión de acción política, a escala planetaria. El resultado de todo ello no puede ser más evidente. Las normas jurídicas emanadas de la Comunidad Internacional/nuevo Estado mundial, no pueden ser ya consideradas como integrantes de un Derecho Internacional que por su propia esencia, y al menos desde Grocio, requiere la concurrencia de dos o más Estados soberanos e independientes. De esta suerte nos encontramos, con que, como muy bien comprendió y denuncio Heller, la conversión de la Comunidad Internacional en una "unidad decisoria planetaria universal y efectiva trasformaría al derecho internacional en derecho estatal", es decir, en auténtico Derecho Constitucional". ${ }^{33}$

La crítica al monismo jurídico radical es más contundente y demoledora: "AI negar la soberanía y al mismo tiempo, afirmar la superioridad del Derecho Internacional

\footnotetext{
31 Ídem.

32 Cfr. Ruiperez Alamillo, J. (2008). "El transfondo teórico-ideológico de la "libertad civil” y su eficacia". Teoría y Realidad Constitucional no 20, pp. 175-230. Cit., p. 225.

33 Ibídem, pp. 226-227.
} 
sobre todo el Derecho interno, lo que en realidad conduce el monismo jurídico radical es que las Constituciones estatales ya no puedan ser entendidas como Lex Superior (... ). El Derecho internacional se configura, desde el monismo jurídico radical, como el gran garante -en rigor el único- de la libertad de los individuos. A hora bien, no puede ignorarse de que se trata de un Derecho Internacional que al no poder presentarse como la voluntad de un pueblo soberano, que, por lo demás, no existe, nunca podrá ocupar la posición que tenían las Constituciones estatales, y en consecuencia, carecerá de esa naturaleza de Derecho Fundamental que le permita conducir adecuadamente la vida jurídica y política de la hipotética aldea global". ${ }^{34}$

3) Desde una perspectiva particular, y porque las propuestas de los nacionalismos de ámbito regional no resultan nuevas, tres son las críticas que se pueden formular, y que también han sido expuestas por el profesor Ruipérez Alamillo: a) En primer lugar no podría acudirse a lo que se ha venido a llamar "Derecho Internacional humanitario" puesto que no se dan los supuestos que él mismo requiere para el ejercicio de la secesión, a saber: 1 . Persecución sistemática de un pueblo o de una minoría étnica, dentro de un Estado multinacional; 2. La desigualdad de Derecho entre los distintos pueblos de un Estado; 3. La desigualdad de hecho en lo que respecta a la protección de las culturas de los distintos pueblos. b) En segundo lugar, en tanto que el Derecho de secesión no es inherente a un Estado Federal, de tal forma que sólo cabe su aplicación si está reconocido expresamente en la Constitución, es evidente que no se trata de un mero olvido del constituyente, sino que la opción de incluir el Derecho de secesión en la Constitución fue expresamente desestimada al rechazarse las enmiendas que a este respecto planteó EE. Así pues no cabe la apelación a un Derecho Humano que el Poder Constituyente expresamente decidió sustraerlo de la libertad civil de los ciudadanos españoles. 3) Por último, lo que se colige del artículo 10.2 de la Constitución es que las normas de Derecho internacional son un criterio principalísimo de interpretación de las normas constitucionales que consagran Derechos Fundamentales (Profesor R. Canosa Usera) y no normas directamente aplicables.

Quiero terminar este subepígrafe, con el intento de conciliar tendencias jurídicopolíticas, haciendo la siguiente reflexión. ¿Es incompatible con el liberalismo político una concepción de la soberanía como única e indivible, y cuyo titular es el Pueblo en su conjunto? Tal sería, como hemos visto, la postura de Rousseau o Heller. Entiendo que la respuesta es negativa, aclarados algunos malentendidos, y debido a las nuevas aportaciones que se han dado dentro de esta corriente de pensamiento. Autores como $\mathrm{H}$. Heller, sin embargo, han llegado incluso a afirmar, que presentar al pueblo como el sujeto de la soberanía es una imposibilidad lógica del liberalismo, ${ }^{35}$ y ello porque para los liberales, según Heller, el pueblo es la suma conceptual de los individuos. De lo que se trata más bien, es de si se alberga una desconfianza hacia el pueblo propia del despotismo ilustrado o más bien, siendo liberal, se es al mismo tiempo, y porque ambas posturas no son incompatibles, demócrata. Se trata de despejar algunos mitos

34 Ibídem, pp. 227 y 228.

35 Cfr. Heller, H. (1995), p. 165. 
erróneos que se han formado los liberales. Un buen ejemplo de tres confusiones propias de algunos neoliberales son las recogidas por el Profesor P. Schwartz en su reciente libro En busca de Montesquieu. La democracia en peligro. En primer lugar afirma, acerca del contrato social de Rousseau que es "texto de poderosa retórica y siniestras resonancias. Es el locus classicus de la teoría de la soberanía popular. El error de Rousseau era creer que el Pueblo no puede ser déspota de sí mismo". ${ }^{36}$ Para este autor, y dado que Rousseau hablaba de "alineación total de cada asociado con todos sus derechos, a toda la comunidad" las consecuencias del pacto social en Rousseau "son mucho más totalitarias que las del Leviatán, pues añade que "dándose a todos, no se da uno a nadie". ${ }^{37}$ Concluye finalmente con una crítica atronadora contra la concepción de soberano de Rousseau de la que dirá: "las notas con las que Rousseau define a ese poder soberano definen con toda claridad el concepto de democracia contra el que insurjo en este ensayo. Refleja la idea de unidad metafísica, inalienable e indivisible, del organismo social constituido por el pacto social". ${ }^{38}$

1) En primer lugar, y como recientemente ha apuntado Mi Maestro, Rousseau no es Hobbes, porque "la noción de los derechos fundamentales se encuentra, aunque de modo implícito, y desde la asimilación de la libertad natural con la libertad civil, en la concepción rousseauniana del contrato social, y en definitiva de la Democracia". ${ }^{39}$ Y ello no es sino la consecuencia lógica de la distinta concepción que del contrato social tienen uno y otro: Hobbes, con una visión pesimista del Estado de naturaleza levanta el Leviatán con el objetivo de lograr la autoconservación de los hombres. Por el contrario Rousseau que tiene una visión idealizada del Estado de naturaleza levanta el pacto social con el objetivo de asegurar la libertad natural, o la libertad civil de los hombres. Por otra parte, parece olvidar el Profesor P. Schwartz que liberalismo y democratismo tienen, como apunto Heller, la misma raíz y precisamente en el contrato social.

2) En segundo lugar, es evidente que resulta ontológicamente imposible que el Pueblo sea déspota consigo mismo. Tampoco ninguna persona puede ser déspota consigo misma. Únicamente caben dos opciones: a) entender que el despotismo sólo cabe de unos (mayoría o minoría) contra otros, b) afirmar, simplemente, y como hace el individualismo metodológico, que el Pueblo como tal no existe y es únicamente la suma de sus individuos. Es precisamente, asumiendo la primera opción por la que entiendo que el liberalismo no sólo es compatible, sino que resulta necesario con la democracia. Insisto, se deben sustituir los parámetros de un liberalismo clásico que tenía más de despotismo ilustrado y que entra en crisis después de 1945, por un liberalismo que tiene, creo yo, un papel fundamental que jugar en las sociedades multiculturales de nuestros días. Tal es el liberalismo teorizado por Jhon Raw Is en su obra El liberalismo político. Para este autor: “El liberalismo político parte del supuesto

\footnotetext{
36 Cfr. SchwarTz, P. (2006), En Busca de Montesquieu. La democracia en peligro (M adrid, Editorial Encuentro), p. 99.

37 Ibídem, p. 100.

38 Ibídem, p. 101.

39 Cfr. Ruiperez Alamillo, J. (2008), p. 215.
} 
de que hay varias doctrinas comprehensivas razonables encontradas, cada una con una concepción del bien y todas ellas compatibles con la plena racionalidad de las personas humanas (en la medida en que esto último puede establecerse con los recursos que proporciona una concepción política de la justicia). (... Esta pluralidad razonable de doctrinas encontradas e inconmensurables se concibe como la realización característica de la razón práctica a lo largo del tiempo y bajo instituciones libres duraderas. De modo que la cuestión que la tradición dominante ha tratado de responder carece de respuesta: ninguna doctrina comprehensiva resulta adecuada como concepción política para un régimen constitucional (la cursiva es mía)" ${ }^{40}$

La idea de justicia política a la que hace referencia J. Rawls se asienta sobre dos principios que el autor define de la siguiente manera:

“a) Todas las personas son iguales en punto a exigir un esquema adecuado de derechos y libertades básicos iguales, esquema que es compatible con el mismo esquema para todos; y en este esquema se garantiza su valor equitativo a las libertades políticas iguales, y sólo a esas libertades.

b) Las desigualdades sociales y económicas tienen que satisfacer dos condiciones: primero, deben andar vinculadas a posiciones y cargos abiertos a todos en condiciones de igualdad equitativa de oportunidades; y segundo, deben promover el mayor beneficio para los miembros menos aventajados de la sociedad" ${ }^{41}$

De esta forma, dice J. Rawls, "el liberalismo político busca una concepción política de la justicia en la esperanza de atraerse, en una sociedad regulada por ella, el apoyo de un consenso entrecruzado de doctrinas religiosas, filosóficas y morales". ${ }^{42}$ Pero lo importante en Rawls, que le diferencia del liberalismo racionalista de Kelsen, es que no habla de una justicia formal sino material y el consenso entrecruzado al que hace referencia no es ni escéptico ni indiferente..$^{43} \mathrm{Es}$, al contrario, un consenso sobre "valores políticos", ${ }^{44}$ que permite que dé un lugar a un verdadero acto constitucional. De un modo, en mi opinión más afortunado, que Rousseau cuando afirmó que el que desobedezca la voluntad general será obligado por el cuerpo social "a ser libre", en el liberalismo propugnado por J. Rawls la justificación del poder público está mejor expresada (aunque no hay diferencias sustanciales, tal como trato de exponer): “(EI) ejercicio del poder político es plenamente adecuado sólo cuando se ejerce de acuerdo con una constitución, la aceptación de cuyos elementos esenciales por parte de todos los ciudadanos, en tanto que libres e iguales, quepa razonablemente esperar a la luz de principios de ideales admisibles para su común razón humana". ${ }^{45}$

Cfr. RAWLS, J. (1996), p. 167.

41 Ibídem, p. 35.

42 Ibídem, p. 40.

43 Ibídem, p. 182.

44 Ibídem, p. 40.

45 Ibídem, p. 169. 
Por consiguiente, el Poder Constituyente es, como decía Donoso Cortés, «el rayo que rasga el seno de la nube, inflama la atmósfera, hiere a la víctima y se extingue», es decir, es soberano, y no es otro que el Pueblo en su conjunto. Sin embargo, porque la soberanía es un concepto de Derecho Político, su ejercicio solo es dable en la esfera de lo público. La soberanía requiere para su ejercicio, homogeneidad, pero ello no excluye la pluralidad.

\section{2) Legitimidad}

Los conceptos de soberanía y legitimidad se encuentran enormemente vinculados, de tal forma que en mi opinión forman un quiasmo según el cual no existe soberanía sin legitimidad ni legitimidad sin soberanía: Desde una perspectiva schmittiana, cabe afirmar que, "una constitución es legítima (... cuando la fuerza y autoridad del Poder Constituyente en que descansa su autoridad es reconocida". ${ }^{46}$ Ello significa que la Constitución del Estado es legítima precisamente por ser la plasmación de la voluntad del soberano, que en el Estado Constitucional actual no puede ser otro que el Pueblo en su conjunto. Efectivamente, porque como ha afirmado el Profesor P. De Vega, la Historia del constitucionalismo no es más que la Historia de las trasformaciones que se han llevado a cabo para hacer reales y efectivas en cada momento las ideas de Libertad y Democracia y en definitiva, hacer a los hombres auténticos ciudadanos libres, es por lo que hoy se puede afirmar, que la clasificación que Carl Schmitt establece entre legitimidad democrática y legitimidad dinástica está hoy completamente obsoleta. Sin embargo, es interesante mencionarla ya que, como también apunta el Profesor P. de Vega ${ }^{47}$ fue en Europa la pervivencia del principio monárquico la que dio lugar a la idea de la doble soberanía.

Así pues, en la actualidad, para poder hablar de Poder Constituyente es necesario que se den los dos requisitos señalados por el profesor P. De Vega: el respeto al principio democrático y que nos encontremos ante una democracia representativa. ${ }^{48}$ No cabe duda de que en España, y por lo general en los países de nuestro entorno, se respeta el principio democrático; sólo una visión demasiado idealista y próxima más bien a la democracia de la identidad podría sostener lo contrario.

Una perspectiva interesante es la que aporta el profesor J.A. Portero Molina. Este autor relaciona conformidad con legitimidad, y así afirmará: "lo mejor que puede decirse de un ordenamiento jurídico es que recoge la opinión del ciudadano común tan satisfactoriamente que la mayoría lo respeta, sin conocerlo, en sus actividades cotidianas, sin el menor esfuerzo". ${ }^{49}$ Establece el profesor Portero la distinción entre legitimidad de origen y legitimidad por eficacia, de tal forma que la conformidad del ciudadano

46 Cfr. ScHmım, C. (1982), Teoría de la Constitución (Traducc. Francisco Ayala. Madrid, Alianza Universidad Textos), p. 104.

47 Cfr. De VegA, P. (1998 a), pp. 42 y ss.

48 Ibídem. p. 25.

49 Cfr. Portero Molina, J.A. (2003), "Legitimidad democrática y Constitución europea”. Revista de Derecho Constitucional Europeo no 3, pp. 11-20. 
con la constitución y los Estatutos de autonomía se produce tanto por su gran legitimidad de origen, ya que todos los ciudadanos participaron, primero con su voto a la asamblea constituyente, y posteriormente con el referéndum de aprobación de la Constitución y de los Estatutos, como por su legitimidad por eficacia, ya que ambos tipos de normas supusieron el comienzo de una nueva etapa de libertades, que trasformó por completo la vida política de los españoles. La legitimidad de los municipios radica en que es entendida por los ciudadanos como la institución de gobierno más próxima.

Decía que este enfoque resulta interesante porque desde esta perspectiva se puede comprender mejor el cambio de paradigma que supone la inclusión de la legitimidad tecnocrática. El Profesor M. García Pelayo enuncia este principio del siguiente modo: “Es legítimo lo que es eficaz, y es eficaz lo que promueve y asegura el desarrollo tecnoeconómico en unas condiciones ambientales y en una coyuntura dada ya que ello es, en última instancia, condición instancia condición para la vigencia de cualesquiera otros valores. Dicho principio tiende a ser, así, en el mundo actual la variable independiente frente a la cual todos los demás criterios de validez serían variables dependientes, contingencias o ritualismos. A esta nueva especie de legitimidad (y con ello, de autoridad) podemos considerarla como la típica legitimidad de la época tecnocrática, una legitimidad de especie racional-funcional, pero en cuyo nombre se pueden justificar fenómenos parciales ilegítimos desde otros principios de legitimidad"..$^{50}$

El que fuera el primer presidente del Tribunal Constitucional adelanta una primera crítica este principio cuando afirma: "Esta preeminencia de la finalidad tecno-económica puede conducir a la subordinación de otros valores y objetivos estatales que pasarán a ser tenidos en cuenta en la medida que sean funcionales o disfuncionales desde el punto de vista tecno-económico, lo cual abre la posibilidad de encubrir intereses de cualquier índole bajo el manto de la eficacia técnica y de justificar la marginación o represión de problemas incómodos para el sistema, so capa de su disfuncionalidad". ${ }^{51}$

Efectivamente, a nadie se le escapa que cuanto más democrático es un régimen es menor el nivel de eficacia pero mayor su eficiencia en la toma de decisiones; $y$ al contrario, los regímenes menos democráticos (aristocracia, monarquía) se caracterizan por un grado mayor de eficacia y un menor nivel de eficiencia. Más adelante enuncia el autor hasta seis críticas diferentes al tecnocratismo, y que por falta de espacio renuncio a trasponer aquí. En todo caso me interesa destacar la que hace referencia al carácter atemporal con el que se presenta el tecnocratismo, que proclama al mismo tiempo que el fin de las ideologías (Bell) su carácter de opción verdadera, tachando a las demás de "ideológicas". Denuncia García Pelayo que esta actitud no es original de los tecnócratas, y que el tecnocratismo implica, efectivamente, una postura ideológica. ${ }^{52}$

El resumen de las seis críticas lo resume el propio autor al final del capítulo de la forma siguiente: "Si bien hoy en día es preciso contar con los métodos tecnocráticos,

50 Cfr. García Pelayo, M. (1982), Burocracia y tecnocracia (Madrid, Alianza Universidad), p. 52.

51 Ídem.

52 Ibídem, pp. 93 y ss. La critica a la afirmación de que el tecnocratismo carece de ideología en la p. 95. 
como en otra época de la historia fue necesario abrir paso a los métodos burocráticos, no es menos cierto que deben ser controlados por una adecuada estructura institucional que neutralice sus malos efectos, que someta a responsabilidad su ejercicio y que convierta a tales métodos en verdaderamente funcionales para la totalidad y no sólo para un subsistema o para los intereses particularizados de un régimen político determinado". ${ }^{53}$

Con la mayor humildad me atrevo a añadir yo a la crítica de quien es uno de los mejores constitucionalistas de la historia española, que el avance vertiginoso de la sociedad tecnocrática supone no pocos problemas y nuevos retos en materia de Derechos Fundamentales, en especial, el derecho a la intimidad, materia sobre la que existen ya numerosos estudios, enfocados principalmente al fenómeno de masas en el que se ha convertido internet.

En todo caso, lo que se debe aceptar sin discusión, es que los Estados Constitucionales modernos son legítimos, tanto por su constitución democrática como por la mejora en las condiciones de vida conocidas en el último tercio del siglo XX.

\section{SOBERANÍA Y LEGITIMIDAD EN EL MARCO DE LA UNIÓN EUROPEA}

\section{1) Soberanía}

Acerca de la soberanía, y en lo que se refiere a la Unión Europea existen dos posturas: 1) La primera es la que niega el carácter constitucional de los tratados, negando por tanto el carácter originario del ordenamiento jurídico de la Unión. Esta postura niega la pretensión del TJCE de la Kompetenz-Kompetenz. Niegan además que la Unión tenga la capacidad de decidir sobre su propio futuro. 2) La postura contraria afirma que ya existe una Constitución Europea, reivindican una constitución propiamente dicha en el sentido prescriptivo del constitucionalismo moderno. Estos autores reclaman la soberanía para la Unión.

La segunda opción, en mi humilde opinión, no es de recibo, y ello por las razones siguientes:

1) La primera y más evidente, es que difícilmente pueden asimilarse los Tratados Constitutivos a una Constitución, en el sentido que el término tiene en el moderno Estado Constitucional, ya que los sujetos que participan en su elaboración son únicamente los Estados. Que sea un poder constituido dentro del Estado (el Gobierno) quien negocia el Tratado en la esfera internacional y otro poder constituido (el Parlamento) el que lo ratifica, sin que ni siquiera haga falta la celebración de referéndum (que por cierto, en ese caso el pueblo opera como poder constituido), hace imposible la consideración de los Tratados a una auténtica constitución.

53 Cfr. García Pelayo, M. (1982), p. 99. 
2) Si como hemos visto en el epígrafe anterior, se admite unánimemente en el constitucionalismo moderno, que el soberano es el pueblo del Estado, que en ejercicio del Poder Constituyente del que es titular, elabora una constitución que pasa a ser la piedra angular de toda la organización jurídico-política del Estado, y desaparece posteriormente, entrando en fase de letargo del que no saldrá hasta que sea necesario dotarse de una nueva constitución, ${ }^{54}$ evidente debiera resultar, que si bien la Constitución de 1978 acusa un evidente carácter europeísta, que se manifiesta en el artículo 93 de la Carta Fundamental, igual de evidente debiera ser, en atención al tenor literal del artículo 93 ("Mediante ley orgánica se podrá autorizar la celebración de tratados por los que se atribuya a una organización internacional el ejercicio de competencias derivadas de la Constitución..."), que se trata en todo momento de una delegación de competencias, que tienen su causa en la voluntad soberana del Pueblo español. Si aplicásemos aquí la máxima romana in claris non fita interpretatio se podría desmontar inmediatamente la pretensión de los que afirman que ya existe una Constitución en Europa, sin embargo, y porque cada vez se repite con más insistencia, sobre todo después del fracaso del Tratado Constitucional de 2004, ahondaremos un poco más en el tema. 21) No es posible considerar que se trata de una mutación constitucional puesto que los límites de la mutación comienzan, como ha puesto de manifiesto el profesor P. De Vega, ${ }^{55}$ cuando se pone en entredicho la misma noción de soberanía. 22) aclarado este extremo, cabe preguntarse si es necesario acudir al procedimiento de reforma constitucional. La respuesta varía dependiendo de la concepción que se tenga acerca de la reforma constitucional: 221) si se sostiene que cabe la reforma total de la constitución, mediante el procedimiento del artículo 168 de la Constitución, entonces la respuesta habrá de ser positiva. 222) si por el contrario se sostiene la tesis, de que incluso allí donde no se han establecido clausulas de intangibilidad, y porque toda constitución se identifica con un régimen político que socialmente la legitima, existen límites implícitos a la reforma constitucional, la respuesta habrá de ser negativa. ${ }^{56}$ Los límites a la reforma constitucional son enunciados, a mi modo de ver de manera impecable, por Carl Schmitt, quien nos dice: "Los límites de reformar la constitución resultan del bien entendido concepto de reforma constitucional. Una facultad de reformar la constitución atribuida por una normación legal-constitucional significa que una o varias regulaciones legal-constitucionales pueden ser sustituidas por otras regulaciones legal-constitucionales, pero sólo en el supuesto de que queden garantizadas la identidad y la continuidad de la Constitución entendida como un todo". ${ }^{57}$

Así pues, por tratarse de una destrucción de la Constitución, ya que utilizando la terminología schmittiana se produciría un cambio no sólo de la Constitución sino también de poder constituyente, la respuesta al interrogante que nos venimos planteando no puede ser sino la de considerar que la cesión de soberanía a la Unión es un tema vetado al poder de reforma, como poder constituido que es.

Cfr. De VegA, P. (1998 a), pp. 24 y sS.

55 Ibídem, pp. 214 y ss.

56 Ibídem, pp. 237 y ss.

57 Sснміт, C. (1982), p. 119. 
3) La tercera crítica tiene relación con la forma de Estado: La Unión Europea es una confederación de Estados en su vertiente moderna (Antonio La Pérgola). ${ }^{58}$ Lo que diferencia principalmente a esta confederación moderna con respecto a la confederación clásica es el efecto directo de determinadas normas de la confederación sobre los ciudadanos; sin embargo, en lógica con lo anterior, la conclusión a la que debe llegarse es que la soberanía, al igual que en la confederación clásica, pertenece al pueblo de los Estados miembros. Debe recordarse en este sentido, que la circunstancia que impide que la Unión Europea pueda ser considerada como una federación, donde, por cierto, la soberanía corresponde al pueblo federal, es precisamente la inexistencia de un pacto social al respecto, como consecuencia, de que no existe un pueblo europeo, debido a la falta de homogeneidad entre los europeos. Prueba de ello, es que cabe en la Unión Europea la retirada voluntaria de un Estado miembro..$^{59}$ A unque tampoco esta cuestión resulta pacífica: la retirada voluntaria de la Unión, recogida de expresamente de esta forma es una innovación del Tratado Constitucional y tampoco se recoge expresamente en el Tratado de Lisboa que entrará en vigor en 2009. Para algunos autores, por ejemplo Fernando Díez M oreno y otros autores como Nicolas Levrat ${ }^{60}$ opinan que un derecho tal resulta contradictorio con un proceso constitucional así como con la naturaleza de las relaciones internacionales. La respuesta una vez más variará según la concepción que se tenga de la soberanía: si como he venido sosteniendo a lo largo de estas páginas, se afirma que la soberanía es única e indivisible y pertenece al pueblo del Estado Constitucional de Derecho, no cabe sino afirmar que, en el seno de una confederación, donde la soberanía reside en el pueblo de los Estados miembros, el ius secesionis es una posibilidad siempre legítima, y ello por la sencilla razón de que el derecho de secesión resulta inherente a la confederación. Incluso es posible en la Federación cuando así sea reconocido por el Poder Constituyente. ${ }^{61}$ Cuando en el seno de una federación un territorio pretende la secesión de forma unilateral, resulta legítimo el empleo de la bundesexekution. ${ }^{62}$

Tras un interesante estudio de Derecho comparado, Miguel Herrero y Rodríguez de Miñón y otros autores del Consejo de Estado, destacan tres constataciones que se derivan del estudio de los hechos referidos a la respuesta constitucional a la integración europea. ${ }^{63}$ 1) En primer lugar la generalización de las fórmulas constitucionales de integración a partir de los tratados constitutivos en los años 50, tan sólo ajenas a los

58 La Pérgola, A. "La Confederación. 2. La forma moderna: "El federalismo y sus contornos", en el volumen Los nuevos senderos del federalismo, Madrid, 1994. Citado en Ruiperez Alamillo, J. (2000). La Constitución europea y la teoría del Poder Constituyente. (M adrid, Biblioteca Nueva), p. 34.

59 Víd. Artículo I-60 del Tratado por el que se establece una Constitución para Europa.

60 Cfr. Levrat, N. "L'apartenance à I'union" en Commentaire de la Constitución de l'union européenne editado por Marianne Dony y Emmanuelle Bribosia. Bruxeles 2005, p. 101.

${ }_{61}$ Cfr. Ruiperez Alamillo, J. (1995). Constitución y autodeterminación. (Madrid, Editorial Tecnos), pp. 77 y ss.

62 Cfr. Ruiperez Alamillo, J. (2003). Proceso constituyente, soberanía y autodeterminación (Madrid, Biblioteca Nueva), pp. 383 y ss.

63 Cfr. Herrero y Rodriguez de Miñón, M.; Jover Gómez-Ferrer J.M.; Roldan Martín, A.; y Amérigo Alonso, J. (2005). "La respuesta constitucional a la integración europea". Revista Española de Derecho Constitucional no 73 (enero-abril), pp. 239-254. Cit., p 253. 
sistemas constitucionales de estricta estirpe británica. 2) En segundo término la tendencia a europeizar las constituciones estatales. 3) En cuanto a las consecuencias de la integración, se afirma, en primer lugar, la supremacía del derecho comunitario, de forma unánime para el derecho ordinario, y con criterios contrapuestos en lo referente al derecho constitucional; en segundo lugar se difunden cláusulas de salvaguarda de la identidad constitucional y de la autonomía institucional del Estado, y por último se difunden progresivamente fórmulas tendentes a asegurar la proyección en el ámbito comunitario de los controles horizontales y verticales sobre el ejecutivo como representante del Estado en dicho ámbito.

Antes de profundizar más en la materia quiero poner de relieve algunos aspectos en los que no comparto la opinión de los autores antes mencionados. Llama mucho la atención en el trabajo la referencia a la limitación de la soberanía que se recoge en el artículo 11 de la Constitución italiana o en el preámbulo de la Constitución francesa de 1946. Pues bien, como apunta la Profesora N. García Gestoso, de la interpretación doctrinal y jurisprudencial del citado precepto se colige que "el artículo 11 permite derogaciones de normas ordinarias de la constitución, pero no puede permitir que la Comunidad Europea derogue los principios del orden constitucional italiano". ${ }^{64}$ La cuestión debiera resultar meridianamente clara por cuanto que la constitución delimita con precisión dichos valores constitucionales, a diferencia de lo que ocurre en el caso español, mediante la inclusión de clausulas de intangibilidad. Podría afirmarse, que lo que permite el artículo 11 es una mutación constitucional que venga propiciada por una realidad fáctica como consecuencia de la integración, pero nunca la destrucción constitucional. Desde una óptica más general, el enfoque extremadamente positivista del estudio le hace perder en mi opinión parte de su riqueza que potencialmente podría albergar. El estudio de la pura letra de la constitución lleva a obviar aspectos tan importantes como la interpretación que de los textos ha sido hecha por los distintos tribunales constitucionales (positivismo jurisprudencial) y el rechazo del pueblo francés al proyecto de Tratado Constitucional (positivismo sociológico). Las carencias en este sentido se ponen tanto más de manifiesto por cuanto precisamente Italia y Francia, junto con Alemania, son, como veremos, de los Estados que más celosos han sido de su soberanía frente al proceso de integración.

A nalizando la jurisprudencia italiana, alemana y francesa, ${ }^{65}$ en comparación con la española, se pueden llegar a conclusiones idénticas, pues en mi opinión existen más diferencias en la forma de expresarlo que en el fondo de la postura de los distintos Tribunales Constitucionales:

1) Por lo que se refiere a Italia, fruto de la tradición jurídica monista de este Estado, el TC italiano venía, como ha apuntado la Profesora N. García Gestoso, equiparando los Tratados comunitarios al resto del ordenamiento jurídico internacional, de forma que unos y otros pasaban a formar parte del ordenamiento jurídico interno italiano. En lógica

${ }^{64}$ Cfr. García Gestoso, N. (2004), p. 92.

65 Cfr. Garcia Gestoso, (2004), pp. 90 y ss. 
con lo anterior ocurría que en virtud del principio lex posterior derogat lex anterior, una ley del Parlamento posterior dejaba sin efecto cualquier disposición de Derecho internacional (que en rigor es ya Derecho interno). Posteriormente, y en atención a la naturaleza especial de las Comunidades Europeas el TC ha abandonado esta jurisprudencia. Sin embargo, cuando se refiere al conflicto entre norma europea frente a constitución, la postura inequívoca de este TC se refleja en la exigencia, previa a la cuestión prejudicial, de plantear ante dicho órgano la cuestión de constitucionalidad. La lógica del TC, que puede compartirse o no, es evidente: no ha lugar a un juicio de conformidad con los Tratados de aquellas normas que sean inconstitucionales; y ello por la sencilla razón de que por serlo, no es posible su aplicación dentro del territorio del Estado.

2) Por lo que respeta al Tribunal Constitucional alemán, si bien en la sentencia Solange I de 1974 afirmaba su competencia para entrar a enjuiciar la constitucionalidad de la normativa comunitaria, esta jurisprudencia se ve alterada en sentencia Solange II de 1986, donde por entender que se había llegado a un momento de equiparación entre el tipo de protección comunitaria y alemana en materia de Derechos Fundamentales rechaza en este caso su competencia para controlar actos de la Comunidad contrarios a tales Derechos. Pero en su sentencia sobre el Tratado de Maastricht, vuelve, como apunta García Gestoso, a sostener una postura incluso más rígida que la que sostuvo en Solange I, que se deriva del gran número de reticencias que manifiesta sobre la necesidad de preservar la soberanía alemana. ${ }^{66}$ Por último en Francia es "donde se ha acudido de manera más nítida al concepto de soberanía para marcar los límites del poder exterior del Estado en general, y en particular, frente al poder de integración comunitario".67 El Conseil d'Etat francés acude a la noción de "condiciones esenciales del ejercicio de la soberanía" para articular su doctrina, aunque entiende que estas pueden ser modificadas mediante la reforma constitucional. La técnica de la reforma en esta materia ha sido criticada, como es fácil imaginarse, por no poca parte de la doctrina francesa, y ello desde dos perspectivas distintas: Favoreu se extraña de que siempre resulte modificada la norma que sirve de referencia y no del texto sometido a examen y Labayle critica la técnica de la revisión-adjunción de un precepto a la Constitución francesa de 1958 para superar el problema de la transferencia de competencias a la UE. ${ }^{68}$

3) Si ahora volvemos nuestra atención al caso español nuestro TC Constitucional afirma, en la Declaración $1 / 2004$, que no existe contradicción entre la Constitución española y el Tratado de Constitución europea. Sobre este pronunciamiento habremos de volver más adelante, pero me interesa ahora destacar, que en concordancia con la jurisprudencia del Tratado de M aastricht del TC alemán y la jurisprudencia del Consejo de Estado francés de 2004, ${ }^{69}$ afirma nuestro TC que: "En el caso difícilmente concebible de que en la ulterior dinámica del Derecho de la Unión Europea llegase a resultar

66 Ibídem, p. 96.

67 Ibídem, p. 98.

68 Cfr. Segura Serrano, A. (2005). “La primacía y el control de constitucionalidad del Derecho comunitario en Francia". Revista española de Derecho Comunitario Europeo (Enero-Abril), pp. 93-132. Cit., p. 105.

69 Ibídem, pp. 127 y ss. 
inconciliable este Derecho con la Constitución española, sin que los hipotéticos excesos del Derecho europeo respecto de la propia Constitución europea fueran remediados por los ordinarios cauces previstos en ésta, en última instancia la conservación de la soberanía del pueblo español y de la supremacía de la Constitución que éste se ha dado podrían llevar a este Tribunal a abordar los problemas que en tal caso se suscitaran, que desde la perspectiva actual se consideran inexistentes, a través de los procedimientos constitucionales pertinentes, ello aparte de que la salvaguarda de la referida soberanía siempre resulta a la postre asegurada por el art. 1-60 del Tratado, verdadero contrapunto de su art. I-6, y que permite definir en su real dimensión la primacía proclamada en este último, incapaz de sobreponerse al ejercicio de una renuncia, que queda reservada a la voluntad soberana, suprema, de los Estados miembros". ${ }^{70}$

A la luz de esta jurisprudencia, quizá se me podría criticar el moverme en el ámbito de las ficciones y supuestos de laboratorio. No es desde luego, ni mucho menos, esa mi pretensión. El planteamiento que intento transmitir en estas páginas me resulta más factible hoy que quizás unos años atrás, y ello debido a los siguientes hechos: 1) las ampliaciones de 2004 y 2007, que han configurado la actual Europa de los 27, con los problemas que comienzan a surgir, en el seno de las instituciones europeas, acerca de la gobernabilidad de la Unión. 2) en segundo lugar, y relacionado con lo anterior, el multiculturalismo, como fenómeno social europeo en el siglo XXI, con los problemas religiosos, étnicos y lingüísticos a los que da lugar, como demuestran no pocos sucesos recientes, de los cuales quizá el más representativo sea el conflicto sobre las caricaturas del profeta Mahoma. 3) la falta de homogeneidad política y social, lleva aparejada, como resulta lógico, la falta de homogeneidad económica. Así por ejemplo, mientras en Francia se fija un sueldo mínimo de unos 1.200 euros, en España, donde el nivel de vida no es tan dispar, resulta aproximadamente de unos 600 euros. En los países del este, de reciente incorporación, el nivel salarial es mucho más bajo. Esto puede, como es lógico, llevar aparejada una deslocalización empresarial, no ya hacia el exterior de las fronteras de Europa (los dragones asiáticos), que cabría neutralizar con medidas proteccionistas a la importación, sino en el mismo interior de Europa. 4) el terrorismo islámico, que tras los atentados de Madrid y Londres ha supuesto una auténtica psicosis por la seguridad que todos los que nos hemos visto obligados a coger un avión hemos sufrido en los aeropuertos. En relación con esto se plantean problemas constitucionales en el seno de la Unión, acerca de la transferencia de los datos personales de los viajeros entre Europa y Estados Unidos, que puede suponer un vulneración del Derecho a la intimidad. 5) Los nacionalismos, de diverso tipo, y de carácter contrapuesto que están apareciendo por doquier dentro de los Estados, y no sólo los de nuestro entorno (cuya conexión con el proceso de mundialización ya se ha señalado, y que de hecho la UE potencia en ocasiones como consecuencia de su política regional). 7) A la vista de las nuevas solicitudes de ingreso en la UE (Turquía y Marruecos) surge la siguiente pregunta: ¿ ¿Dónde se sitúan las fronteras de Europa? Es difícil dar una respuesta clara a la luz de los acontecimientos señalados.

70 Vid. Declaración 1/2004 de 13 de febrero de 2004, fundamento jurídico 4ㅇ․ 
Para terminar, expongo brevemente una crítica a las teorías de la soberanía divisible y el principio de competencia en el ámbito comunitario. ${ }^{71}$ Sucintamente se puede decir que la primera consiste en afirmar que el Estado no pierde soberanía, sino que, gracias a su participación en el proceso de decisión comunitario tiene la posibilidad de ejercer funciones que había perdido en el ámbito puramente interno en el plano estatal. El corolario de ello es entender que la UE está dotada a su vez de derechos propios de soberanía. Entienden estos autores que la soberanía puede entenderse como un conjunto de poderes y que por lo tanto permite la transmisión de los mismos de un modo irreversible. ${ }^{72}$ Una variante de esta doctrina es la teoría de la soberanía en la UE expuesta por A ntonio La Pérgola, ${ }^{73}$ según la cual la soberanía ha de reconocerse tanto al Parlamento europeo, como representante del Pueblo europeo, como a los Pueblos de los distintos Estados miembros. En cuanto a la teoría de la sustitución del concepto de soberanía por el de competencia niega rotundamente que el concepto de soberanía como explicatorio del momento actual de la integración europea. ${ }^{74}$

Confieso que no alcanzo a ver una diferencia sustancial entre uno y otro planteamiento. En el plano teórico que mientras una se mueve en el paradigma de la soberanía como concepto que explica las relaciones internacionales, la otra sencillamente niega dicho concepto. Lo cierto es que, a mi modo de ver, ambas terminan por establecer un catálogo de, Ilámeseles derechos soberanos, llámeseles competencias, inalienables, y que, por tanto, ambas instituciones deben de respetar. La idea de dividir la soberanía, concebida clásicamente como única, indivisible e inalienable no es, en mi humilde opinión, sino una negación del concepto mismo de soberanía, y ello aunque no se diga expresamente. En cuanto a la teoría que aboga por la sustitución del concepto de soberanía por el de competencia merece, a mi modo de ver las siguientes críticas: y es que no sirve, en primer lugar, para solucionar los posibles conflictos que pueden surgir a consecuencia de la inflación normativa a la que estamos asistiendo en la actualidad. En efecto, en nuestros días el individuo se halla sometido a una multitud de normas emanadas de distintas esferas, local, regional, nacional, supranacional, y entre las que puede surgir el conflicto. El criterio de competencia puede servir como una primera aproximación al problema, de tal modo que la norma que debe prevalecer es aquella que ha sido dictada por el órgano competente para ello. Pero resulta que es difícil que una norma cualquiera afecte sólo a un determinado ámbito y no tenga repercusiones en otros ámbitos. En estos casos, y porque estaríamos ante dos sujetos de derecho iguales (Estado y UE), el conflicto tendería a recrudecerse, y el criterio de la competencia no ofrecería, ultima ratio, solución alguna al problema. En segundo lugar, y más importante, esfumado el concepto de soberanía negado el concepto de soberanía, se produce una quiebra irreparable del principio democrático, que es uno de los dos pilares del constitucionalismo moderno, pues se habría desposeído al Pueblo del Estado de la condición de soberano, lo que operando desde los

\footnotetext{
Cfr. García Gestoso, N. (2004), pp. 101 y ss.

Ibídem, p. 102.

Cfr. exposición y crítica en Ruiperez Alamillo, J. (2000), pp. 157 y ss.

74 Ibídem, p. 106.
} 
esos parámetros justificaría legítimamente una merma de los derechos de participación de los mismos en la toma de decisiones. ¿Quién puede negar que esto sea así, y más cuando claramente estamos asistiendo a ese proceso ya en nuestros días? Finalmente, la variante de la doctrina de la separación de poderes que propone el profesor italiano mejora la formulación de la doble soberanía en el sentido en que invoca no tanto un catálogo de derechos so beranos distintos para uno y otro titular de la soberanía como la idea de aunar la voluntad de ambos sujetos en una única voluntad soberana. Lo que ocurre, es que como ya señaló Carl Friedrich, no es posible reconocer dos o más soberanos en un mismo territorio. Tal pretensión supone también una perversión del concepto clásico de soberanía que cobra así un significado confuso.

\section{2) Legitimidad}

Volvamos, llegados a este punto, al magnífico ensayo del Profesor J.A. Portero M olina para debatir acerca de la legitimidad en la Unión Europea. El razonamiento que plantea no podría ser más evidente: Por un lado afirma que tanto por motivos de legitimidad de origen implícita en la voluntad europeísta de los ciudadanos en el momento en que se redactó la Constitución de 1978, y que se pone de manifiesto si se atiende al artículo 93 de la Carta Fundamental, como por motivos, sobre todo, de legitimidad por eficacia, que se plasma en la mejora que ha supuesto de las condiciones de vida de la ciudadanía, es posible explicar la pertenencia a la Unión, y por ello que los ciudadanos se vean inmersos en un ordenamiento jurídico sobre el que nunca se han manifestado expresamente. Pero a continuación explica que "Es evidente, con todo, que la aparición ahora de la Constitución europea, redactada por una Convención, supone un salto cualitativo respecto de la situación ahora vivida en el curso de un largo proceso y requiere, por tanto, plantearse las cosas a la luz de una nueva dimensión que aporta la firma y posterior ratificación de un Tratado, que no es uno más de la larga lista, sino del Tratado por el que se instituye la Constitución que crea la Unión Europea". ${ }^{75}$

Esta cita recoge dos aspectos importantes: el primero es que, al ser la Constitución europea redactada por una Convención, más recuerda, en mi opinión, a una carta real otorgada, propia de la época de la restauración, que a una constitución en el sentido del constitucionalismo moderno del siglo XX. En segundo lugar, que aunque formalmente es un Tratado, y por ello se emplean los cauces jurídicos para la aprobación de los Tratados, materialmente es mucho más.

Así pues, a diferencia de lo que la mayoría de los internacionalistas sostienen, que la Constitución Europea es un Tratado y es una Constitución, en mi opinión, habría que decirse que esta no es, en rigor, ni un Tratado (solo lo es en un sentido formal), ni desde luego una Constitución. No comparto, sin embargo, la afirmación del Profesor J.A. Portero Molina, cuando afirma que a su juicio una reforma parcial del artículo 93, por el

75 Portero Molina, J.A. (2005), p. 14. 
procedimiento ordinario de reforma previsto en el 167, en el sentido de hacer una mención expresa a la Unión Europea que permita la cesión de competencias derivadas de la nuestra Norma Superior a dicha Institución. En opinión de este autor, de esta forma "La CE seguirá siendo la (norma) suprema, salvo en lo que haya cedido la supremacía a la Constitución y el Derecho Comunitario, respecto de lo cual, siempre queda la vía abierta a la recuperación de la supremacía por la CE".$^{76}$ En todo caso, aclara el Profesor, que la reforma no es obligada pero sí recomendada. En el momento en que fue escrito el artículo, aún no se había pronunciado el TC acerca de la constitucionalidad del Tratado, quizá por ello se emplean indistintamente supremacía y primacía, al igual que lo hizo el propio Tribunal Constitucional en la Declaración de 1992. ${ }^{.7}$ Sin embargo, en su Declaración 1/2004 el Alto Tribunal ha otorgado un significado distinto a ambas palabras: en efecto si acudimos de nuevo al fundamento jurídico 4 을 de la sentencia se nos dice que "Primacía y supremacía son categorías que se desenvuelven en órdenes diferenciados. Aquélla, en el de la aplicación de normas válidas; ésta, en el de los procedimientos de normación. La supremacía se sustenta en el carácter jerárquico superior de una norma y, por ello, es fuente de validez de las que le están infraordenadas, con la consecuencia, pues, de la invalidez de éstas si contravienen lo dispuesto imperativamente en aquélla. La primacía, en cambio, no se sustenta necesariamente en la jerarquía, sino en la distinción entre ámbitos de aplicación de diferentes normas, en principio válidas, de las cuales, sin embargo, una o unas de ellas tienen capacidad de desplazar a otras en virtud de su aplicación preferente o prevalente debida a diferentes razones. Toda supremacía implica, en principio, primacía (de ahí su utilización en ocasiones equivalente, así en nuestra Declaración 1/1992, FJ 1), salvo que la misma norma suprema haya previsto, en algún ámbito, su propio desplazamiento o inaplicación".

Se colige fácilmente pues que la cesión de supremacía, por ser inherente al concepto de Constitución, implicaría la destrucción de la Carta Fundamental de 1978, lo que no puede llevarse a cabo por el procedimiento de reforma, ni siquiera por el procedimiento agravado del artículo 168 , según la postura que vengo defendiendo a lo largo de estas páginas. No me parece pues, necesaria ni recomendable la reforma del artículo 93, y no alcanzo la doble ventaja que señala el Profesor JA. Portero M olina, a saber, "claridad de expresión y garantizar para el futuro que la atribución de competencias siempre requerirá la previa conformidad de España", ${ }^{78}$ cuando prácticamente nadie duda que ese artículo de la Constitución fue redactado pensando precisamente en una futura incorporación a las Comunidades europeas, y en el mismo se señala, con meridiana claridad, que lo que es objeto de cesión es "el ejercicio de competencias derivadas de la Constitución". M uy al contrario, me parece que la reforma es jurídicamente innecesaria y políticamente peligrosa, pues podría servir de argumento a los euro-optimistas, para la afirmación de un nuevo modelo de relaciones jerárquicas entre los Estados y la Unión, cuando aun de realizarse, la intención sería muy otra.

\footnotetext{
Ibídem, p. 17.

77 Cfr. Roldan Barbero, J. y Diez Peralta, E. (2006), “Tribunal Constitucional español y Derecho Comunitario (2003-2005)". Revista de Derecho Comunitario no 23, pp. 87-133.

78 Portero Molina, J.A. (2005), p. 17.
} 
En fin, ocurre que como decíamos, si es posible reconocer la legitimidad por eficacia de la Unión, que hasta ahora ha venido a fortalecer las libertades civiles de los individuos, como con meridiana claridad apunta el Profesor de la Universidad de La Coruña "no sería posible sostener un balance así de positivo tras un contraste entre las posibilidades amplias que a las exigencias democráticas de participación y control depara la Constitución española y las mínimas que ofrece el Derecho Comunitario", ${ }^{79}$ y termina diciendo que "la enorme distancia que le separa de las instancias de poder europeo, es lo que permite determinar la ingente tarea que queda por hacer para que la Unión Europea se asiente sobre las bases políticas democráticas de modo inequívoco". ${ }^{80}$

Si profundizamos en las construcciones teóricas acerca de la legitimidad por eficacia de la Unión, nos encontramos, siguiendo al Profesor A. Cantaro, con dos tipos de legitimación: La legitimación por el Derecho y la Legitimación por los derechos. Dentro de esta última dedica un capítulo aparte a los derechos sociales.

La primera significa que, en palabras del Profesor A. Cantaro: "Una Europa Constitucionalmente sin nación, sin Estado, sin pueblo; una Europa institucionalmente sin vértice, sin centro, produce un vacío de legitimación que debe ser colmado. Por un nuevo soberano: el derecho de los Tratados, los derechos fundamentales, la jurisprudencia, la administración, los expertos, la clase de los juristas".

Este "maximalismo jurídico"81 ha dado lugar a un proceso de constitucionalización, que requiere a su vez de una federalización de las relaciones entre la Unión Europea y los Estados miembros. Para ello junto a una serie de principios expresamente recogidos en los Tratados se han elaborado por parte del TJCE una serie de principios que no vienen recogidos en los Tratados: autonomía, primacía, y efecto directo, junto con unos poderes implícitos para la tutela de los derechos fundamentales. De esta forma, afirma Cantaro, aunque el ordenamiento comunitario no conoce ni la ley ni el principio de legalidad en el sentido tradicional de los términos se ve dotada de su propia legalidad comunitaria. ${ }^{82}$ Concluye ese apartado, el Profesor A . Cantaro, afirmando que la Constitución europea recuerda en gran medida a la Groundnorm Kelseniana puesto que "propone (presupone), el problema de la legitimidad, pero lo deja sin resolver". ${ }^{83}$ En realidad, si nos ajustamos al esquema trazado, no es tanto que no resuelva el problema de la legitimidad como que ofrece una respuesta únicamente para la legitimación por eficacia. La respuesta, a mi modo de ver, no es sin embargo, en absoluto satisfactoria, y ello porque cuando hablamos de legitimación por eficacia de lo que se trata es de analizar si se ha mejorado efectivamente la condición de vida de los ciudadanos. Pues bien, si tenemos en cuenta que los ciudadanos europeos ya disponían de unas considerables condiciones de vida, gracias al marco de protección de los derechos constitucionales creado tras la

Ibídem, p. 19.

80 Ibídem, p. 20.

81 Ibídem, p. 91.

82 Ibídem, p. 99.

83 Ibídem, p. 106. 
conclusión de la Segunda Guerra Mundial en 1945, la creación de un nuevo ordenamiento jurídico, per se, es decir, en el sentido de un sistema de gradación de las normas jurídicas, no ayuda en nada a mejorar las condiciones de vida de los ciudadanos. De lo que se trata es de averiguar si ese ordenamiento jurídico sirve efectivamente, para crear un marco de protección a los nuevos retos que la mundialización económica y la revolución en los sistemas de información y nuevas tecnologías plantean, y que los Estados nacionales tenían dificultades para solucionar por ser estos, fenómenos que traspasan las fronteras estatales. Si esto es así, resultaría efectivamente, que el proceso de integración supondría, no un debilitamiento, sino al contrario, un fortalecimiento del Estado al recuperar funciones que había perdido debido a la creciente dependencia interestatal. Para dar respuesta a esta pregunta es necesario analizar los tipos de derechos que reconoce el ordenamiento en cuestión.

El segundo tipo de legitimación que señala el Profesor A. Cantaro es la legitimación por los Derechos: ${ }^{84}$ La Tutela de los derechos fundamentales se convierte así, y en virtud de lo sentado por el TJCE en un principio fundador de la Unión Europea y presupuesto indispensable de su legitimidad. Para ello el marco de referencia obligado es la Carta de Niza de 2000. Lo que ocurre, es que esta Carta de Derechos Fundamentales de la Unión adolece de una serie de déficits de distinto tipo. El Profesor A. Cantaro señala tres: 1) déficit democrático-institucional; 2) un déficit axiológico; 3) un déficit de juridicidad. ${ }^{85}$ El primero de ellos se debe al alejamiento de los ciudadanos de la toma de decisiones, que no participaron en la elaboración de la constitución, que fue creada por una Convención que no fue elegida por sufragio. El déficit axiológico se explica por la denuncia que algunos hacen de la falta de consideración de la carta de los valores sociales y de la solidaridad. Por último el déficit de juridicidad alude a que la Carta no está dotada aún (¡El Tratado de Lisboa no está en vigor!), de fuerza jurídica vinculante. Ligado con lo anterior se hace referencia a los derechos sociales y a su equiparación con los demás derechos fundamentales. ${ }^{86}$ Tras constatar el elevado número de derechos del catálogo, efectúa el Profesor A. Cantaro dos críticas al sistema. La primera hace referencia a la dificultad que a causa de la equiparación con los derechos civiles y políticos se produce para una correcta gradación, y a la postre, adecuada ponderación entre derechos para los casos de conflicto. La segunda crítica se debe al debilitamiento de la distinción entre derechos fundamentales y no fundamentales, y como consecuencia de ello, de la noción misma de Derecho Fundamental. ${ }^{87} \mathrm{La}$ conclusión de todo ello es, a mi juicio la siguiente, y debería llamarnos la atención acerca de que la legitimación por eficacia de la Unión no es, ni mucho menos, perfecta: la proliferación de derechos políticos, civiles y sociales no siempre lleva aparejada un mayor nivel de protección y una mejora en las condiciones de la ciudadanía. ${ }^{88}$

84 Ibídem, pp. 107 y ss.

85 Ibídem, p. 119.

86 Ibídem, pp. 129 y ss.

87 Ibídem, p. 136.

88 En el mismo sentido se ha manifestado, por ejemplo, Prieto Barcelona, en una reciente conferencia ofrecida los días 26 y 27 de febrero (2008) en la Universidad de La Coruña. También lo ha apuntado mi Maestro, el Profesor J. Rupérez (Cfr. RuIPEREz AlamilLo, J. (2006), El Constitucionalismo democrático en 
Si analizamos las razones que al parecer supusieron el rechazo del pueblo francés y holandés a la Constitución Europea podemos extraer algunas conclusiones que no hacen sino reforzar las posiciones que vengo sosteniendo en este trabajo: establece Jean-Claude Piris que los factores que incidieron en el rechazo en referéndum de la Constitución Europea fueron: 1) La situación económica interna, 2) La falta de popularidad del Gobierno del momento, 3) la falta de información al electorado. ${ }^{89}$ Las dos primeras causas hacen referencia a cómo los electores interpretan y ofrecen respuestas a los problemas europeos cuando se les pregunta, en clave nacional. La tercera pone de manifiesto el tan acusado déficit democrático de la Unión, que se traduce, en un alejamiento, percibido por los ciudadanos, de las instancias de poder. La relación es clara: como consecuencia del alejamiento se produce la interpretación de los asuntos en clave nacional.

\section{EL DERECHO ESTATAL Y DERECHO COMUNITARIO}

\section{1) El principio de primacía}

Como es bien sabido, tres son, fundamentalmente, los principios que rigen las relaciones entre el Derecho comunitario y el Derecho estatal: el principio de autonomía del Derecho comunitario, según el cual el Derecho comunitario es un ordenamiento jurídico propio, autónomo, tanto del Derecho internacional como del Derecho estatal; el principio de eficacia directa del Derecho comunitario supone que ciertas normas del derecho comunitario producen por sí mismas efectos plenos, y de manera uniforme en todos los Estados miembros, a partir de su entrada en vigor, y durante todo el periodo de su validez, y ello sin necesidad de un acto de recepción por parte de los Estados miembros; por último, el principio de primacía del derecho comunitario, según el cual las normas de Derecho comunitario resultan de aplicación preferente frente a las disposiciones de Derecho interno. En los dos primeros, por ser indiscutidos, y por guardar una relación menor con el presente trabajo no voy a detenerme más.

El principio de primacía ha sido y es más discutido no sólo en la doctrina sino también en el seno mismo de la Unión: si bien se admite de forma unánime respecto de las normas de Derecho ordinario, se han vertido, como ya he indicado, opiniones de distinto signo acerca de si este principio es predicable por lo que respecta a las normas Constitucionales.

El principio de primacía se enuncia por el TJCE en la sentencia Costa c. ENEL de $1964,{ }^{90}$ y el tribunal lo sostiene, como ha señalado la Profesora A. Mangas Martín, en

los tiempos de la globalización. Reflexiones rousseaunianas en defensa del Estado constitucional, democrático y social (M exico, UNAM), p. 84.

89 Cfr. PIRIS, J.C. (2006), El Tratado Constitucional para Europa. Un análisis jurídico (M adrid Marcial Pons), p. 55.

90 Vid. STJCE de 15.7.1964. Costa C. ENEL. A sunto 6/64. 
torno a cuatro tipos de consideraciones: $1^{\text {}}$ ) Según la naturaleza y características de las CCEE, que gozan de poderes efectivos que emanan de una limitación de competencias o transferencias de atribuciones de los Estados a la Comunidad. 2º) La primacía se basa también en el carácter obligatorio que el artículo 249 de TCE confiere a las normas de Derecho derivado. 3ㅇ) El compromiso del cumplimiento leal de los Tratados aceptado expresamente por todo Estado miembro, que les impide llevar a cabo actos que pongan en peligro la realización de los objetivos de los Tratados (art. 10 TCE). 4o) Por último, los Estados han admitido que el Derecho de los Tratados se aplique sin discriminación de la nacionalidad de los particulares (art. 12). ${ }^{91}$ También señala la Profesora A. Mangas cuatro principios nuevos, que a su parecer se deducen de la sentencia Simmenthal, ${ }^{92}$ y que serían los siguientes: 1 을 el primero que una norma comunitario hace inaplicable de pleno derecho, desde el momento mismo de su entrada en vigor, toda legislación nacional anterior contraria a la misma. 2ํ) La vigencia de una norma comunitaria impide la formación válida de nuevos actos legislativos nacionales que fueran incompatibles con la misma. 3을 El órgano judicial no debe esperar a que la norma incompatible sea derogada ni plantear la cuestión de inconstitucionalidad. 4ㅇ) El cuarto es que el juez del litigio concreto puede y debe excluir la norma interna y aplicar la norma comunitaria. ${ }^{93}$

Nada tengo que objetar yo, si de lo que hablamos es de la primacía del Derecho comunitario frente al Derecho interno, excepto en el tercer principio deducido por la profesora A raceli $M$ angas de la sentencia Simmenthal: es una injerencia intolerable, para lo que el TJCE carece absolutamente de competencia, el determinar cuándo el juez nacional debe plantear o no la cuestión de inconstitucionalidad, puesto que es un tema estrictamente de Derecho procesal interno. La razón de tal exceso es fácilmente comprensible y ya ha sido apuntada: de lo que se trataba aquí era de mantener un pulso con el tribunal constitucional italiano, el cual requería la previa cuestión de inconstitucionalidad a la cuestión prejudicial.

Pero si de lo que se trata es de anteponer la primacía del DC a la Constitución de los Estados miembros, hay que decir que ello, sencillamente, no resulta de recibo. No lo es, en absoluto, por las siguientes razones:

1) Porque la soberanía es, como digo, naturalmente ilimitada, absoluta e inalienable, cae por sí mismo el argumento basado en la doble soberanía, que en palabras de la Profesora A. M angas se enuncia de la siguiente manera: "La Constitución es la expresión de la voluntad soberana de los pueblos y en ella reside el fundamento de adhesión de un Estado a la Unión Europea, al prever la atribución de competencias y la aceptación de todas sus características. No cabe hablar de superioridad del DC sobre la Constitución ni cabe hablar de un conflicto entre la Constitución y normas comunitarias: la Constitución

91 Cfr. Mangas Martin, A. y Liñan Nogueiras, J. (2007), Instituciones y Derecho de la Unión Europea. (Madrid, Editorial Tecnos), pp. 405 y ss.

92 Vid. STJCE de 9. 3.1978, Simmenthal, Asunto 106/77.

93 Ibídem, p. 428. 
se aplica en los ámbitos que siguen siendo competencia del Estado miembro, pero en los ámbitos atribuidos a la Unión, y regulados por normas comunitarias se aplica el Derecho comunitario en toda su plenitud y el Estado no puede invocar la Constitución para impedir los efectos de la norma comunitaria válida".

Efectivamente, porque la Constitución es el fundamento de la validez y aplicabilidad del Derecho comunitario sobre el territorio del Estado, resulta por ello ontológicamente imposible afirmar que la Constitución sirve de fundamento a normas que abiertamente la contradicen. Ello nos lleva a concluir que porque la soberanía no es divisible, los actos de las instituciones europeas serán validos y aplicables en el territorio nacional mientras no estén en abierta contradicción con la Constitución. Cuestión distinta es, por supuesto, que una situación en la que un acto derivado es conforme a los Tratados y a su vez contrario a la Constitución de un Estado miembro sea difícilmente imaginable en la coyuntura actual. Cabe recordar, que si es la voluntad soberana del pueblo la de seguir avanzando en la integración europea, cabría siempre el recurso a la reforma constitucional o bien a la creación de una nueva Constitución. Comprendo plenamente que para lograr una armonización y una homogeneidad del DC es necesario el principio de primacía, pero lo que deben comprender aquellos que lo predican respecto a las normas constitucionales, es que el fin no justifica los medios; en todo caso resulta imaginable la elaboración de un Pacto Social a nivel europeo, que dé lugar a la existencia de un Pueblo europeo que elabore una Constitución, la cual sería superadora de las Constituciones estatales actuales. Mientras esa hipótesis no se verifique no es posible confundir los deseos políticos e ideológicos, legítimos en todo caso, con la verdad jurídica.

2) Es frecuentemente repetido, para justificar el principio de primacía, la invocación de la máxima pacta sunt servanda, pero este principio no resulta aplicable cuando de normas constitucionales se trata: porque de lo que se trata es de una delegación de competencias soberanas derivada de la Constitución, según se desprende por ejemplo del artículo 93 de nuestro Texto Fundamental, no cabe, como es lógico, que los órganos delegatarios, opongan tal cláusula frente al delegante, el Pueblo del Estado Soberano, cuya voluntad está expresada en la Constitución, y que no cabe jamás confundir, como otrora hizo Sieyés, con la voluntad de los representantes.

3) Si cabe el control de constitucionalidad sobre el Derecho originario, cuanto más debiera predicarse del Derecho derivado, que por requerir un nivel de consenso menor, es más susceptible de ser contrario a los principios constitucionales de los Estados M iembros. ${ }^{94}$ Así pues, de consolidarse la opción contraria, a lo que llevaría el proceso de integración sería, al menos potencialmente, a una disminución de las garantías propias del Estado Constitucional; y ello porque cabría la posibilidad de que una norma con efectos jurídicos plenos en el plano estatal resultase conforme a los Tratados pero contraria a la Constitución. Tampoco es una situación tan imposible: no es tan difícil imaginar

94 Quiero reflejar aquí mi agradecimiento al Catedrático de la Universidad de La Coruña, el Dr. Pedro Serna Bermúdez, quien nos hizo este valioso comentario durante una clase del Máster de Estudios de la Unión Europea, para el cual presenté este trabajo como Memoria final. 
situaciones en las cuales, entre los diversos sentidos que puede tomar el desarrollo de un precepto contenido en un Tratado, sin vulnerarlo, tomando un sentido resulte acorde o no a la Constitución de un Estado M iembro. Incluso, y este es el quid de la cuestión, dependiendo de que el desarrollo se haga en un sentido u en otro, puede resultar constitucional en unos Estados M iembros e inconstitucional en otros.

Lo que debe provocar la reacción democrática más contundente contra el actual proceso de integración europea, que no es ya que esté influenciado por la máxima montesquiana de "todo para el pueblo pero sin el pueblo" sino que, dando un paso más, opera según un principio de "todo para el pueblo, incluso en contra del pueblo", desde los esquemas del tecnocratismo neoliberal más radical y antidemocrático. En lo que a nosotros nos interesa, esta actitud se ve reflejada en la evolución del Principio de Primacía. Este nace, como hemos explicado, de la jurisprudencia del TJCE, que por cierto no es una fuente de Derecho Comunitario, y fue incorporado a la Constitución Europea (art. I-6), que, como se sabe, fracasó. Pues bien, el 22 de junio de 2007 el Servicio Jurídico del Consejo elabora un dictamen en el que se afirma lo siguiente: "De la jurisprudencia del Tribunal de Justicia se desprende que la primacía del derecho comunitario es un principio fundamental de dicho Derecho. (... ) Y esta es también la situación actual. El hecho de que el principio de primacía no aparezca recogido en el futuro Tratado no modificará en absoluto la existencia de este principio ni la jurisprudencia en vigor del Tribunal de Justicia".

Como se ve, el obscurantismo y la simulación parecen ser los principios que sustituyen al principio democrático y a la transparencia en la UE.

En mi humilde opinión, la consecuencia es la siguiente: La primacía es una atribución constitucional a favor de las Comunidades Europeas, con el objetivo de hacer posible la homogeneidad del Derecho Comunitario; y por ello no podrá ser nunca predicada en contra de lo que disponen las Constituciones de los Estados M iembros.

\section{2) Derechos Fundamentales en la Unión}

a) Contenido. Con anterioridad al año 1969, el TJCE se negaba a entrar en cuestiones relativas a los Derechos Humanos por considerar que caen fuera del ámbito de aplicación del Derecho Comunitario. Pero a partir de 1969 se produce un giro jurisprudencial, señalado por el profesor Carillo Salcedo ${ }^{95}$ y el tribunal reconoce que: 1) "Ios derechos fundamentales de la persona están comprendidos dentro de los principios generales del derecho comunitario cuyo respeto garantiza el Tribunal de Justicia" ${ }^{96}$ 2) Que la protección de estos Derechos Humanos está inspirada en las tradiciones constitucionales de los Estados miembros. ${ }^{97}$ 3) Junto con las tradiciones constituciona-

\footnotetext{
Ibídem, p 114 y ss.

Vid. STJCE de 12 de noviembre de 1969 (caso Standder).

97 Cfr. Carrillo Salcedo, J.A. (2003), El Convenio Europeo de Derechos Humanos (M adrid, Editorial Tecnos), p. 114. Víd. también STJCE caso Internationale Handelsgesellschaft, de 1970.
} 
les de los Estados miembros, los principios generales pueden ser también deducidos de los textos internacionales y especialmente del Convenio Europeo de Derechos Humanos. ${ }^{98}$ Las razones de este giro jurisprudencial son expuestas claramente por el mismo autor: "El giro jurisprudencial (... o obedeció a la preocupación del Tribunal de Justicia de las Comunidades Europeas por encontrar una respuesta adecuada a la posición que habían adoptado los Tribunales Constitucionales alemán e italiano, que se negaron a aceptar la primacía del Derecho Comunitario sobre normas constitucionales internas garantizadoras de derechos y libertades individuales". ${ }^{99}$

A partir de este momento, la protección de los Derechos Humanos en el ámbito comunitario fue construida casuísticamente por el TJCE, que fue reconociendo en distintas sentencias derechos tales como la propiedad, libre ejercicio de una actividad económica, reagrupación familiar, derecho de defensa, libertad religiosa, etc. ${ }^{100}$

Desde que en 1979 en un memorándum de la Comisión al Consejo se propusiera la incorporación de la UE, como organización internacional, al Convenio Europeo de Derechos Humanos, ${ }^{101}$ esta ha sido una necesidad que se ha venido exponiendo de forma recurrente por actores y teorizadores de la UE. El Consejo de Ministros solicitó en 1995 al TJCE que emitiera un dictamen acerca de la posibilidad de adherirse al Convenio de Roma, y en su Dictamen 1/1996, de 28 de marzo, el TJCE respondió negativamente, afirmando que la UE no tenía competencia, atribuida en los Tratados, en materia de Derechos Humanos. A la luz de la respuesta del TJCE comenzó a gestarse la idea de adoptar un catálogo propio de Derechos Humanos, que tuvo como resultado la aprobación de la Carta de Niza en 2000. La aprobación de este catálogo de Derechos Fundamentales de la Unión no implicó que se desechase la idea de incorporar a la UE como tal, y a pesar de que todos los Estados de la UE forman ya parte del Consejo de Europa, al CEDH. Así entendían algunos, como el Profesor J.A. Carrillo Salcedo que "La adopción de un catálogo propio de derechos fundamentales por parte de la Unión Europea va a favorecer, sin duda, la seguridad jurídica; pero la adhesión de la Comunidad Europea al Convenio Europeo de Derechos Humanos reforzaría aún más la importancia de los derechos humanos en el proceso de integración europea y tendría la ventaja -(... ) - de someter también a la Comunidad y a su Tribunal de Justicia, al control del Tribunal Europeo de Derechos Humanos". ${ }^{102}$

El actual Tratado de la Unión Europea contiene, en su artículo 6.2 (redacción otorgada por el Tratado de Ámsterdam), y tras afirmar en el apartado anterior que la Unión se basa en los principios de Democracia y Libertad, lo siguiente: "La Unión respetará los derechos fundamentales tal y como se garantizan en el Convenio Europeo para la Protección de los Derechos Humanos y de las Libertades Fundamentales firmado en Roma el 4 de noviembre de 1950, y tal y como resultan de las tradiciones constitucionales comunes a los Estados miembros como principios generales del Derecho comunitario".

\footnotetext{
98 Cfr. Carrillo Salcedo, J.A. (2003), p. 114, y también Víd. STJCE de 14 de mayo de 1974 (caso Nold).

99 Cfr. Carrillo Salcedo, J.A. (2003), p. 115.

100 Ibídem.

101 Ibídem, p. 123.

102 Ibídem, p. 127.
} 
Con esta redacción seguía sin ser posible la adhesión al Convenio, por no implicar un título competencial a favor de la Comunidad. La Carta se divide en 6 títulos, sin relación de jerarquía entre ellos, que rezan como sigue: Dignidad, Libertades, Igualdad, Solidaridad, Ciudadanía, y por último Justicia.

Carrillo Salcedo resume las características de la Carta en tres fundamentalmente: 1) La Carta no establece, como vimos, distinción alguna entre los Derechos Civiles, Políticos y Sociales siendo así un instrumento original respecto de los textos jurídicos europeos y universales. La Crítica a esta técnica ha sido efectuada, de la mano de A. Cantaro más arriba y a ella me remito. 2) En segundo lugar no establece diferencia alguna en el reconocimiento de los derechos con independencia de la nacionalidad y el lugar de residencia, a excepción de los derechos de ciudadanía y aquellos destinados a sujetos especiales. 3) En tercer lugar la Carta reconoce derechos que sin ser nuevos, aspiran a hacer frente a los nuevos desafíos que implican las nuevas tecnologías. ${ }^{103}$

Pero esta Carta, aprobada por la Convención formada tras el Consejo de Tampere no fue incorporada al Tratado de Niza, lo que es igual a decir que los Estados miembros no desearon dotarla de fuerza jurídica vinculante. Aún así, el Profesor JA. Carillo Salcedo insiste en que es un documento jurídico, y no sólo político, debido a que, parafraseando a García de Enterría, por "estar redactada en la lengua de los derechos". ${ }^{104}$ A esta razón habría que añadir que el TJCE la ha venido utilizando como método de interpretación en la aplicación del Derecho Comunitario, y ha querido ser reconocida también por el legislador comunitario en no pocos instrumentos normativos. Sin embargo, aun reconociendo, como acabo de hacer, el valor jurídico de la Carta de Niza, que duda puede caber, de que se trata de un sistema de garantías que ofrece mucha menos protección y un muy menor grado de seguridad jurídica, precisamente debido a su falta de vinculación para los poderes públicos.

Si esto es así, desde las bases del constitucionalismo democrático y social, y para no experimentar un retroceso respecto de los avances obtenidos en materia de Derechos Humanos desde 1945 hasta nuestros días, la conclusión ha de ser evidente: no cabe afirmar la primacía del Derecho Comunitario sobre las normas constitucionales de Derechos Fundamentales, por la sencilla razón de que estas siguen ofreciendo, al día de hoy, un menor nivel de protección.

La situación cambiará radicalmente de entrar en vigor el Tratado de Lisboa aprobado en $2007,{ }^{105}$ pues en su art. 6 que creo, habla por sí solo, afirma literalmente que:

«Artículo 6.

1. La Unión reconoce los derechos, libertades y principios enunciados en la Carta de los Derechos Fundamentales de la Unión Europea de 7 de diciembre de 2000, tal como fue adaptada el 12 de diciembre de 2007 en Estrasburgo, la cual tendrá el mismo valor jurídico que los Tratados.

\footnotetext{
103 Ibídem, pp. 119 y 120.

104 Ibídem, p. 121.

105 Publicado en el Diario Oficial $n^{\circ} \mathrm{C} 306$ de 17 diciembre 2007. Como es sabido, estaba previsto su entrada en vigor el 1 de enero del 2009 pero esta no se ha producido por el no referendario de Irlanda.
} 
Las disposiciones de la Carta no ampliarán en modo alguno competencias de la Unión tal como se definen en los Tratados.

Los derechos, libertades y principios enunciados en la Carta se interpretarán con arreglo a las disposiciones generales del título VII de la Carta por las que se rige su interpretación y aplicación y teniendo debidamente en cuenta las explicaciones a que se hace referencia en la Carta, que indican las fuentes de dichas disposiciones.

2. La Unión se adherirá al Convenio Europeo para la Protección de los Derechos Humanos y de las Libertades Fundamentales. Esta adhesión no modificará las competencias de la Unión que se definen en los Tratados.

3. Los derechos fundamentales que garantiza el Convenio Europeo para la Protección de los Derechos Humanos y de las Libertades Fundamentales y los que son fruto de las tradiciones constitucionales comunes a los Estados miembros formarán parte del Derecho de la Unión como principios generales.»

b) Distribución de competencias. En el artículo 6 TCE, en la nueva redacción que le otorga el Tratado de Lisboa, tanto en lo que se refiere a la adhesión al CEDH como en lo que se refiere al reconocimiento del contenido de la Carta de Derechos Fundamentales de 2000, se afirma solemnemente que el reconocimiento de unos y otros no implican una modificación de las competencias tal y como vienen contenidas en los Tratados. Esta afirmación se contenía ya en el artículo 51.2 de la Carta de Niza y ha servido de inspiración a la técnica empleada, en el ámbito subestatal, por los nuevos Estatutos de Autonomía. ${ }^{106}$ El nuevo Tratado de Lisboa sustituye el actual artículo 5 del TCE por el artículo 3 "ter".

«A rtículo 5. La Comunidad actuará dentro de los límites de las competencias que le atribuye el presente Tratado y de los objetivos que éste le asigna.

En los ámbitos que no sean de su competencia exclusiva, la Comunidad intervendrá, conforme al principio de subsidiariedad, sólo en la medida en que los objetivos de la acción pretendida no puedan ser alcanzados de manera suficiente por los Estados miembros, y, por consiguiente, puedan lograrse mejor, debido a la dimensión o a los efectos de la acción contemplada, a nivel comunitario.

Ninguna acción de la Comunidad excederá de lo necesario para alcanzar los objetivos del presente Tratado.»

«A rtículo 3 ter.

1. La delimitación de las competencias de la Unión se rige por el principio de atribución. El ejercicio de las competencias de la Unión se rige por los principios de subsidiariedad y proporcionalidad.

2. En virtud del principio de atribución, la Unión actúa dentro de los límites de las competencias que le atribuyen los Estados miembros en los Tratados para lograr los objetivos que éstos determinan. Toda competencia no atribuida a la Unión en los Tratados corresponde a los Estados miembros.

3. En virtud del principio de subsidiariedad, en los ámbitos que no sean de su competencia exclusiva, la Unión intervendrá sólo en caso de que, y en la medida en

${ }^{106}$ Víd. a modo de ejemplo, art. 37.4 del Estatuto de Autonomía de Cataluña. Únicamente en el Estatuto de la Comunidad Valenciana no contiene esta prevención. 
que, los objetivos de la acción pretendida no puedan ser alcanzados de manera suficiente por los Estados miembros, ni a nivel central ni a nivel regional y local, sino que puedan alcanzarse mejor, debido a la dimensión o a los efectos de la acción pretendida, a escala de la Unión.

Las instituciones de la Unión ap licarán el principio de subsidiariedad de conformidad con el Protocolo sobre la aplicación de los principios de subsidiariedad y proporcionalidad. Los Parlamentos nacionales velarán por el respeto del principio de subsidiariedad con arreglo al procedimiento establecido en el mencionado Protocolo.

4. En virtud del principio de proporcionalidad, el contenido y la forma de la acción de la Unión no excederán de lo necesario para alcanzar los objetivos de los Tratados.

Las instituciones de la Unión aplicarán el principio de proporcionalidad de conformidad con el Protocolo sobre la aplicación de los principios de subsidiariedad y proporcionalidad.».

En virtud del artículo 5, las competencias implícitas son aquellas que la Unión puede abrogarse, siempre respetando el principio de subsidiariedad, cuando éstas fueran necesarias para el cumplimiento de los objetivos mencionados en los Tratados. A hora, con la redacción del apartado 2 del artículo 3 "ter" no cabe en absoluto la defensa de la existencia de competencias implícitas. En efecto ahora se dice que la Unión actuará en el ámbito de sus competencias que le atribuyen los tratados para lograr los objetivos que estos determinen. Por si cabía al guna duda se añade que toda competencia que no esté atribuida expresamente en los Tratados corresponde a los Estados miembros (principio de atribución). Anteriormente se decía que la Unión actuaba en el marco de las competencias y objetivos expresados en los Tratados. La razón es fácilmente imaginable: los Derechos Fundamentales son, por su propia naturaleza universales. De seguirse afirmando que la Unión podía actuar en virtud de los objetivos que le atribuyen los Tratados incluso sin competencia expresa para ello, la UE dispondría de competencias implícitas, prácticamente ilimitadas (¡todas! excepto organización territorial e institucional de los Estados), fundamentadas todas ellas en la defensa de los Derechos Humanos. La consecuencia práctica es posible sintetizarla en una sola frase: Los Derechos Humanos son reconocidos en la UE sólo en lo que se refiere a la aplicación del Derecho Comunitario. ${ }^{107}$ Dicho en otras palabras, la UE no se convierte en una instancia supranacional de protección de los Derechos Humanos (ello es, en rigor, como es sabido, el Consejo de Europa).

La solución parece coherente y respetuosa con la soberanía de los Estados miembros, y se presenta como un argumento para afirmar que no es posible ya, alegar dificultad alguna para la aplicación del principio de primacía del Derecho Comunitario. La cuestión sin embargo no es tan sencilla y suscita algunos interrogantes y problemas para el jurista perspicaz. Dado que no hay alteración de la soberanía ni de las competencias de los Estados miembros, las Constituciones nacionales siguen siendo expresión de la voluntad del pueblo y norma suprema del ordenamiento jurídico. Los Derechos Fundamentales reconocidos en estas Cartas Fundamentales siguen teniendo vocación universal y es el máximo intérprete de la Constitución (TC o cualquier otro

107 Víd. también las explicaciones a la Carta de Derechos Fundamentales publicado en el Diario O ficial el 14 de diciembre de 2007. 
órgano designado como tal en los distintos Estados europeos) quien tiene, como es lógico, la última palabra acerca del alcance de los mismos. Por eso la última jurisprudencia del TC alemán, italiano, y de todos los demás sigue siendo la pauta de interpretación de las relaciones entre los ordenamientos jurídicos nacional y comunitario.

c) Posición en el ordenamiento interno. La posición de la Carta de los Derechos Fundamentales de la Unión Europea ocupa en el ordenamiento interno de los Estados la misma posición que los Tratados. La adhesión al CEDH vincula únicamente a los poderes públicos de la Unión y a los Estados miembros en la medida en que todos ellos han suscrito individualmente el Convenio. En cuanto al alcance concreto de la expresión "la misma posición que los Tratados" me remito a la crítica al monismo jurídico expuesta más arriba.

A sí las cosas y dado que, como dice el Profesor P. De Vega: "Entendido el tiempo y el espacio como realidades y marcos de la Res Pública, el único planteamiento correcto de la política y la democracia no puede ser otro que el que, siguiendo metodológicamente el realismo maquiavélico, debe realizarse tomando el Estado como ámbito primordial de la vida política democrática". ${ }^{108}$

De manera que sigue siendo el Estado el principal garante de los DDFF, la proliferación de declaraciones de derechos, en el ámbito europeo y regional, que implica procesos de federalización contrapuestos de debilitamiento del Estado, supone afirmar un menor estatus de los DDFF en la actualidad.

\section{BIBLIOGRA FÍA}

\section{A) Monografías}

Bodino, J. (1985). Los Seis Libros de la República (Madrid, Editorial Tecnos).

CANTARO, A . (2006). Europa Soberana. La Constitución de la Unión entre guerra y derechos (Barcelona, El Viejo Topo).

Carrillo Salcedo, J.A. (2003). El Convenio Europeo de Derechos Humanos (Madrid, Editorial Tecnos).

De VEGA, P. (1998 a). “La reforma constitucional y la problemática del poder constituyente" (Madrid, Editorial Tecnos).

Dony, M. y BRiBosiA, E. (2005). Commentaire de la Constitución de l'union européenne editado por M arianne Dony y Emmanuelle Bribosia (Bruxeles).

Garcia Gestoso, N. (2004). Soberanía y Unión Europea (Algunas cuestiones críticas desde la Teoría de la Constitución). (Barcelona, A telier).

Garcia Pelayo, M. (1982). Burocracia y tecnocracia (Madrid, Alianza Universidad).

HelleR, H. (1995). La Soberanía. Contribución a la teoría del derecho estatal y del derecho interestatal (M éxico, FCE).

JelLINEK, G. Teoría general del Estado (Granada, Editorial Comares).

${ }^{108}$ De VegA, P. (2003), p. 42. 
Mangas Martin, A. y Liñan Nogueiras, J. (2007). Instituciones y Derecho de la Unión Europea (Madrid, Editorial Tecnos).

PIRIS, J.C. (2006). El Tratado Constitucional para Europa. Un análisis jurídico (Madrid Marcial Pons).

Rawls, J. (1996). El liberalismo político (Barcelona, Editorial Crítica).

Ruiperez A lam ILLo, J. (1995). Constitución y autodeterminación (M adrid, Editorial Tecnos).

Ruiperez Alamillo, J. (2006). El Constitucionalismo democrático en los tiempos de la globalización. Reflexiones rousseaunianas en defensa del Estado constitucional, democrático y social (M exico, UNAM).

Ruiperez Alamillo, J. (2000). La Constitución europea y la teoría del Poder Constituyente (Madrid, Biblioteca Nueva).

Ruiperez Alamillo, J. (2003). Proceso constituyente, soberanía y autodeterminación (Madrid, Biblioteca Nueva).

Schmitr, C. (1998). Teología Política. Cuatro ensayos sobre la soberanía (Buenos Aires, Editorial Struart \& Cía).

Schm Iт, C. (1982). Teoría de la Constitución (Traducc. Francisco A yala. Madrid, Alianza Universidad Textos).

Scwartz. P. (2006). En busca de Montesquieu. La democracia en peligro (Madrid, Editorial Encuentro).

B) Artículos de Revista

De Vega, P. (1998 b). “El tránsito del positivismo jurídico al positivismo jurisprudencial en la doctrina constitucional". Teoría y Realidad Constitucional no 1, pp. 65-88.

De Vega, P. (2003). "La democracia como proceso. (Consideraciones en torno al republicanismo de M aquiavelo). Revista de Estudios Políticos no 120 (Abril-Junio), pp. 7-43.

De Vega, P. (1998 c). “Mundialización y Derecho Constitucional. La crisis del principio democrático en el constitucionalismo actual". Revista de Estudios Políticos no 100, pp. 13-56.

Díez-Picazo, L.M. (2006). “Límites internacionales al Poder Constituyente”. Revista Española de Derecho Constitucional no 76 (Enero-Abril), pp. 9-32.

Estevez Araujo, J. (M ayo 98). “Disolución de la soberanía y fragmentación de la ciudadanía en el proceso de integración europea". Revista Internacional de Filosofía Política no 11 , pp. 5-17.

Herrero y Rodríguez de Miñón, M.; Jover Gómez-Ferrer, J.M.; Roldán M artín, A.; y A mérigo A lonso, J. (2005). "La respuesta constitucional a la integración europea". Revista Española de Derecho Constitucional no 73 (Enero-A bril), pp. 239-254.

Portero Molina, J.A. (2003). "Legitimidad democrática y Constitución europea". Revista de Derecho Constitucional Europeo no 3, pp. 11-20.

Roldán Barbero, J. y Díez Peralta, E. (2006). "Tribunal Constitucional español y Derecho Comunitario (2003-2005)". Revista de Derecho Comunitario no 23, pp. 87-133.

Ruiperez Alamillo, J. (2008). “El transfondo teórico-ideológico de la "libertad civil” y su eficacia". Teoría y Realidad Constitucional no 20, pp. 175-230.

Segura Serrano, A. (2005). "La primacía y el control de constitucionalidad del Derecho comunitario en Francia". Revista Española de Derecho Comunitario Europeo (enero-abril), pp. 93-132. 